University of Nebraska - Lincoln

DigitalCommons@University of Nebraska - Lincoln

April 2006

\title{
Protein Structure Similarity Clustering: Dynamic Treatment of PDB Structures Facilitates Clustering
}

\author{
Bradley D. Charette \\ University of Nebraska - Lincoln \\ Richard G. MacDonald \\ University of Nebraska - Lincoln \\ Stefan Wetzel \\ University of Nebraska - Lincoln \\ David B. Berkowitz \\ University of Nebraska - Lincoln, dberkowitz1@unl.edu \\ Herbert Waldmann \\ University of Nebraska - Lincoln
}

Follow this and additional works at: https://digitalcommons.unl.edu/chemistryberkowitz

Part of the Chemistry Commons

Charette, Bradley D.; MacDonald, Richard G.; Wetzel, Stefan; Berkowitz, David B.; and Waldmann, Herbert, "Protein Structure Similarity Clustering: Dynamic Treatment of PDB Structures Facilitates Clustering" (2006). David Berkowitz Publications. 1.

https://digitalcommons.unl.edu/chemistryberkowitz/1

This Article is brought to you for free and open access by the Published Research - Department of Chemistry at DigitalCommons@University of Nebraska - Lincoln. It has been accepted for inclusion in David Berkowitz Publications by an authorized administrator of DigitalCommons@University of Nebraska - Lincoln. 


\section{Communications}

\section{Protein Structures}

\section{Protein Structure Similarity Clustering: Dynamic Treatment of PDB Structures Facilitates Clustering ${ }^{\dagger}$}

\author{
Bradley D. Charette, Richard G. MacDonald, Stefan \\ Wetzel, David B. Berkowitz, * Herbert Waldmann*
}

Keywords - biological information, combinatorial chemistry, molecular dynamics, protein structures, target selection

\section{* B. D. Charette, Prof. D. B. Berkowitz Department of Chemistry University of Nebraska Lincoln, NE 68588 (USA) \\ Fax: (+1) 402-472-9402 \\ E-mail: dbb@unlserve.unl.edu \\ S. Wetzel, Prof. H. Waldmann \\ Max-Planck-Institut für Molekulare Physiologie \\ Abteilung für Chemische Biologie \\ Otto-Hahn-Strasse 11, 44227 Dortmund (Germany) and \\ Universität Dortmund \\ Fachbereich 3, Chemische Biologie \\ Fax: (+49) 231-133-2499 \\ E-mail: herbert.waldmann@mpi-dortmund.mpg.de \\ Prof. R. G. MacDonald \\ Department of Biochemistry \& Molecular Biology \\ University of Nebraska Medical Center \\ Omaha, NE 68198 (USA) \\ + This research was supported by the Max-Planck-Ge- sellschaft, the Deutsche Forschungsgemeinschaft, and the Fonds der Chemischen Industrie. D.B.B. thanks the Max-Planck-Gesellschaft (sabbatical stay), the Amer- ican Heart Association (GIA 0650014Z), and NIH (CA 62034 and RR016544-01) for support. B.D.C. acknowl- edges a UCARE fellowship. R.G.M. acknowledges sup- port from the NIH (CA 91885). We thank Dr. Ingrid R. Vetter for useful discussions. PDB=protein data bank.}

$\mathrm{P}$ rotein structure similarity clustering (PSSC) [1]- [3] is one of a number of potential guiding principles [4], [5] that have been introduced to focus combinatorial-library design/protein targeting. PSSC clusters protein targets with similar ligand-binding cores in which little sequence or functional similarity is evident. Lead compounds for one member of the cluster then provide novel starting points in chemical space for ligand development for other members of the PSSC.

We describe herein a new clustering procedure that lends itself to ligand docking, molecular dynamics (MD), and the vector-alignment-search-tool (VAST) [6] algorithm. This MDassisted approach offers an alternative to the serial structure retrieval/inspection steps used to generate the original protein structure similarity cluster, centered on Cdc25A. [2] Furthermore, in a particularly difficult de novo test, the mannose 6phosphate/insulin-like growth factor II receptor (M6P/IGF2R), lends itself to clustering, with MD opening up connections to partners that the static crystal structure coordinates fail to find.

Ortholand and Ganesan [7] have described the disappointing early yield of clinical candidates from combinatorial chemistry/high-throughput screening as a "paradise lost" sentiment, probably attributable to unreasonable expectations and the need for maturation in approaches to combinatorial library design. [8] Both diversity-oriented synthesis (DOS) and biology-oriented synthesis (BIOS) have arisen in response to the this need. DOS utilizes more-complex, often fused polycyclic frameworks, richer in stereochemistry and frequently functionalizes them through annulation or coupling reactions. [9] Within BIOS, [10] biological relevance and prevalidation are employed as key arguments for the design of natural-productderived/inspired [3], [11] compound collections.

PSSC seeks to add value to such compound libraries by grouping targets into otherwise unrecognized clusters. In this way, a BIOS library, originally directed at enzymes of a specific functional or homology family, can be redirected at a PSSC partner protein and produce novel leads for this target. PSSC groups proteins based on a comparison of extracted "ligand-sensing cores," are independent of sequence or functional similarity. Importantly, core extraction is independent of domain or fold constraints and involves carving out a sphere around a key ligand or protein-based center in the binding pocket. This approach is complementary to a number of interesting, surface pattern recognition methods that compare binding pockets based upon exposed protein surface pseudocenters (CavBase, [12] SiteEngine [13]), triangles (pvSOAR), [14] cavities, [15] or residues (efSite, [16] PINTS [17]), and to the all atom approach exemplified by SitesBase. [18]

The PSSC approach begins in biological space and seeks to first identify a cluster of targets of pharmaceutical or bioorganic interest and then looks for an appropriate lead scaffold, drawing from binding data for one member of the cluster. The notion of a PSS cluster is related to the concept advanced by Sternberg and co-workers of "supersites," reflecting binding-site similarity in the absence of homology. [19] PSSC also resonates with interesting ideas put forth by Quinn and co-workers, [20] suggesting that structural motifs used to bind intermediates in enzymes along a biosynthetic pathway for a natural product might also be used to find (unrelated) target proteins for that same natural product.

The original identification of a PSS cluster [2] began from the single available X-ray crystal structure (1C25) [21] for the catalytic core of Cdc25A, a dual-specificity protein phosphatase (Figure 1). The Cdc isozymes may represent novel chemotherapeutic targets. [22] Initial structure similarity searches by using the combinatorial extension (CE) [23] and Dali-FSSP (families of structurally similar proteins) [24] algorithms connected Cdc25A with hydroxynitrile lyase (3YAS) [25] and methylene methanopterin dehydrogenase (1LU9), [26] respectively.

These initial cluster members indicated that the parent 


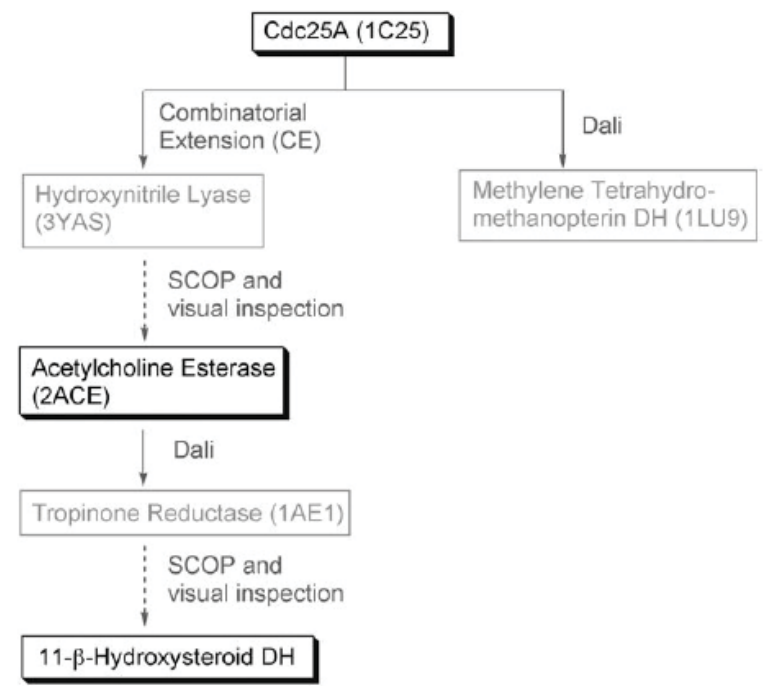

Figure 1. The pathway taken by Koch [2] to establish the original PSS cluster. Note the use of SCOP and intuition/manual inspection

dual-specificity phosphatase could be related to proteins capable of promoting nucleophilic addition to carbonyl centers (perhaps presaging carboxyl esterase activity) and with nicotinamide-dependent dehydrogenase activity. Koch and coworkers next used SCOP (structural classification of proteins; scop@mrc-lmb.cam.ac.uk), a database from the MRC (The Medical Research Council, Cabridge, UK) that groups evolutionarily proteins based on conserved structural elements. [2], [27] In this way, beginning from the 3YAS lead, structurally related proteins could be located, retrieved, DaliLite [4] or CE pairwise-aligned, and examined by visual inspection (Figure 1). This pathway led to acetylcholinesterase (AChE) as a PSS partner for Cdc25A (see Table 1).

\begin{tabular}{|c|c|c|c|c|}
\hline Time $[p s]^{[a]}$ & $\begin{array}{l}\text { Alignment } \\
\text { length } \\
(\mathrm{AChE}- \\
1 \mathrm{H} 22)^{[\mathrm{b}]}\end{array}$ & $\begin{array}{l}\text { RMSD }[\AA]] \\
(\mathrm{AChE}- \\
1 \mathrm{H} 22)^{[\mathrm{b}]}\end{array}$ & $\begin{array}{l}\text { Alignment } \\
\text { length }(11 \beta- \\
\text { HSDH-1XSE- } \\
\text { A) }\end{array}$ & $\begin{array}{l}\text { RMSD }[\hat{A}] \\
(11 \beta-H S D H- \\
1 X S E-A)^{|c|}\end{array}$ \\
\hline 0 & 88 & 6.0 & 85 & 4.2 \\
\hline 100 & 90 & 6.3 & 90 & 4.5 \\
\hline 200 & 90 & 5.9 & 81 & 3.6 \\
\hline 300 & 70 & 3.4 & 81 & 3.5 \\
\hline 400 & 95 & 5.7 & 80 & 3.6 \\
\hline 500 & 86 & 3.7 & 96 & 4.8 \\
\hline 600 & 86 & 4.0 & 88 & 4.3 \\
\hline $700^{[d]}$ & 91 & 4.3 & 90 & 3.9 \\
\hline 800 & 86 & 3.9 & 91 & 4.8 \\
\hline 900 & 79 & 5.0 & 93 & 5.0 \\
\hline 1000 & 83 & 4.5 & 92 & 5.4 \\
\hline
\end{tabular}

[a] Representative conformers at 100-ps intervals in the MD simulation on the Cdc25A-dysidiolide docked structure. [b] Results of a DaliLite pairwise comparison with the $1 \mathrm{H} 22$ acetylcholinesterase crystal structure. [c] Results of a DaliLite pairwise comparison with the $11 \beta$-hydroxysteroid dehydrogenase structure 1XSE, molecule $A$ in the unit cell. [d] Data in bold highlights the time region in which the simulation samples Cdc25A conformations that align especially well with these cluster partners.
A second iteration of this sequence was then carried out. This time, the Dali structural alignment identified tropinone reductase as an AChE partner. The idea that pyridine nucleotide-based dehydrogenases (DHs) might be in this PSSC had been foreshadowed by the initial 1LU9 hit. Indeed, manual inspection of the Rossmann fold superfamily, analogous to the earlier SCOP step, then led from tropinone reductase to $11 \beta_{-}$ hydroxysteroid dehydrogenase (11 $\beta$-HSDH). Eventually, a 147-member library based on the sesterterpene Cdc25A inhibitor, dysidiolide, [28] also produced inhibitors for both $\mathrm{AChE}$ and 11 -HSDH (see the Supporting Information). [2]

Motivated by the success of this de novo application of PSSC to generate a target cluster that responds to a naturalproduct-inspired combinatorial library, we set out to examine the clustering protocol more closely. Namely, the initial formulation of this PSSC required two labor-intensive SCOP/superfamily searching steps (Figure 1). This meant the serial retrieval of a good number of PDB coordinate sets for cluster candidates and their evaluation for active-site structural homology with the catalytic core of Cdc25A. This was necessitated because available web-based structural comparison algorithms, including CE, [23] Dali, [24] and VAST, [6] all fail to find either AChE or $11 \beta-\mathrm{HSDH}$ as structural homologues when starting from $1 \mathrm{C} 25$, the only available structure for $\mathrm{Cd}-$ c25A.

Given that such structure-comparison algorithms are usually limited to searching a static set of crystallographic coordinates in the PDB, we wondered whether introducing dynamics [29] would facilitate the structure-homology search. The notion is simply that the crystallographic snapshot of a protein that is deposited in the PDB is likely to be one of a number of conformations that an approaching ligand might encounter in solution. If one could begin from an array of conformations that Cdc25A likely samples in protein structure space, then a structural comparison might be able to identify PSSC partners that would not otherwise appear.

Toward this end, (-)-dysidiolide was initially docked with the 1C25 structure by using Autodock 3.0. [30] Then, a onenanosecond MD simulation was carried out on the docked structure (Gromacs [31], Figure 2), collecting snapshots every picosecond. To analyze the variations in backbone confor-

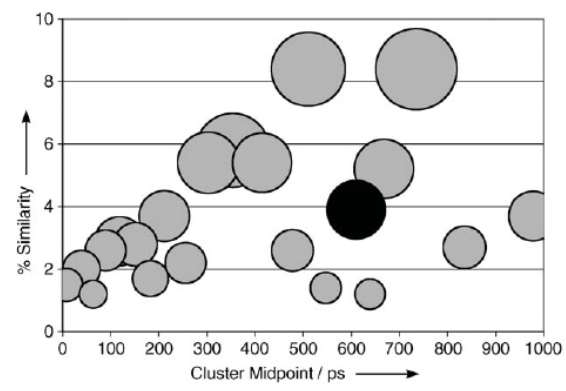

Figure 2. Cluster distribution of the 1000 conformers resulting from the MD simulation (Gromacs) on the dysidiolidedocked Cdc25A structure shown in Figure 3. All clusters with more than 10 members are shown as a function of the time of appearance of the midpoint conformer. Circle diameters are proportional to cluster size. The midpoint conformer of the black-shaded cluster is shown in Figure 3. 
mation with time, along the simulation, pairwise comparisons with the structures of AChE (1H22) [32] and of ( $11 \beta-\mathrm{HSDH}-1$ (1XSE-A) [33] were performed at 100-ps intervals (see Table 1 for results). In particular, one notices that in the 600-700-ps regime, the conformations of $\mathrm{Cdc} 25 \mathrm{~A}$ being sampled apparently show greater structural homology with these two PSSC partner proteins.

The 1000 Cdc25A conformations sampled were clustered by using Gromos [31] (Figure 2). Of a total of 60 conformational clusters found, 26 have more than 10 members. The three most populated clusters only begin to appear near the midpoint, probably reflecting a large conformational change associated with "flap closure" dominating the initial part of the simulation. This motion is quite apparent from an animation of the MD simulation (see the Supporting Information) and can be inferred from a comparison of early and late snapshots (Figure 3).

The midpoint conformers of each of the top ten clusters were arbitrarily sampled for their ability to find members of the original PSS cluster (Figure 1). By using the VAST algorithm, all 10 midpoint conformers find hydroxynitrile lyase (HNL) and four find methylene tetrahydromethanopterin DH (MTHMP $\mathrm{DH})$, which were the only two PSS partners that were initially identifiable from the static 1C25 structure. Pleasingly, however, a VAST search initiated from conformer 668 (midpoint of the cluster shaded black in Figure 2) finds all five members of the Cdc25A cluster. More specifically, this conformer hits a significant fraction of the available structures for these proteins in the PDB: HNL (22/23), MTHMP DH (2/2), tropinone reductase (3/6), AChE (14/66), and 11ß-HSDH (1/6).

VAST finds good alignment of conformer 668 with $11 \beta_{-}$ HSDH-1(1XEA) in the following regions (residues 37-56, 63-66, 69-77, 91-98, 100-112, and 124-133). If one follows the average root mean square deviation (RMSD) for $\mathrm{C}_{\alpha}$ atoms across these residues, relative to their position in the starting conformer, there is a sharp increase from approximately $0.7-1$ $\AA$ in the time regime of $600-800$ ps. Consistent with this, the conformer at $700 \mathrm{ps}$ also finds four of the five cluster members (see the Supporting Information). A structural overlay of conformer 668 with AChE and $11 \beta-\mathrm{HSDH}-1$ is presented in Figure 3 (bottom).

In light of the success of MD to open up new structural alignments with VAST, we next set our sights on a de novo test of the protocol. In this regard, a particularly difficult case was chosen; namely, the cation-independent, M6P-IGF2R (see Figure 4). [34] This large 300-kDa transmembrane receptor contains 15 homologous extracytoplasmic repeats. Domains 3 and 9 are known to have a high affinity for M6P. The receptor binds M6P-functionalized proteins and IGF-II independently (domain 11). In addition to serving a range of housekeeping functions associated primarily with channeling proteins to the lysosomes, the receptor is known to internalize circulating IGF-II and hence has been labeled a cancer-suppressor gene. [35] Internalization appears to be accelerated by M6P-type ligand binding, [36] increasing interest in high-affinity ligands for this site. [37]

Only three PDB entries are available for the M6P-sens-
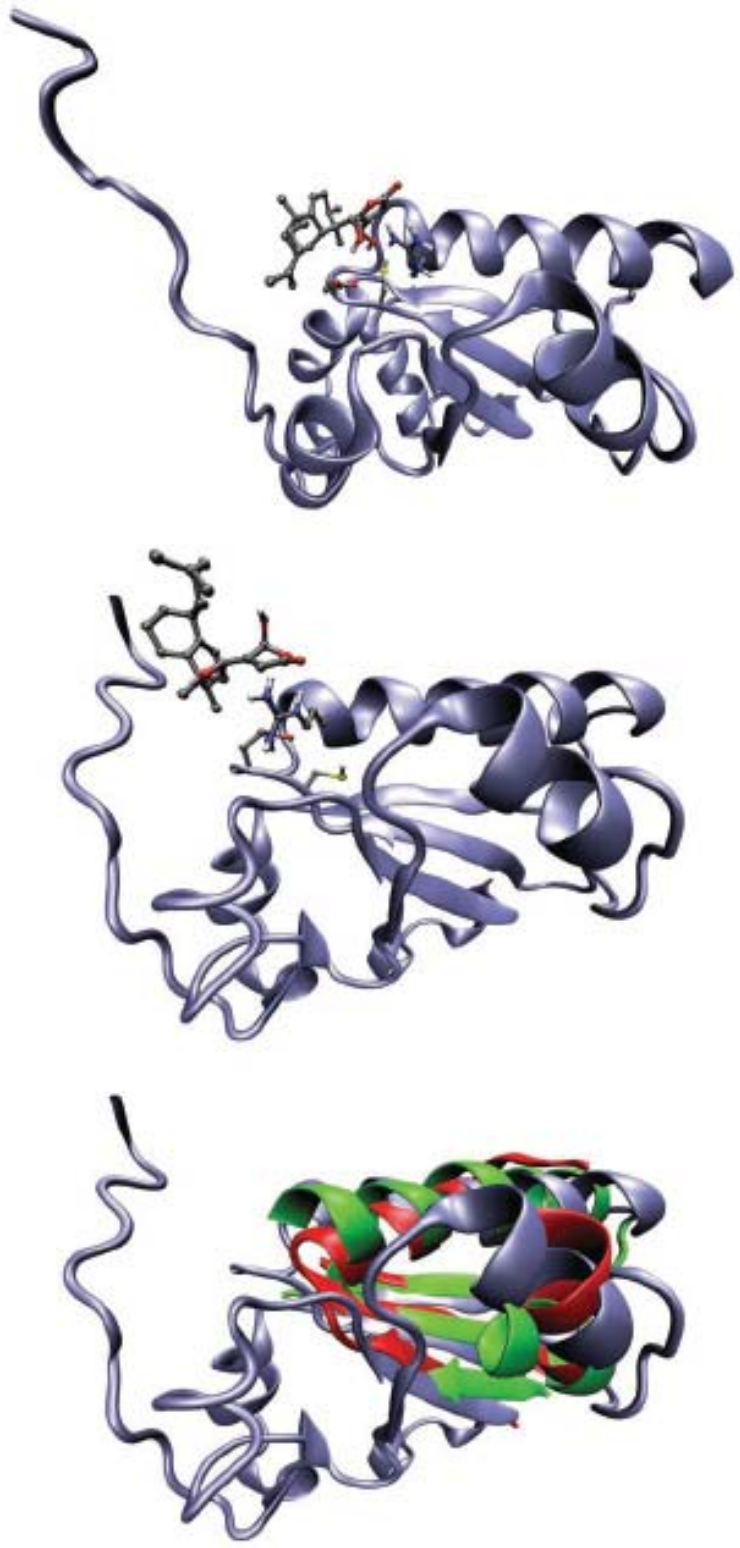

Figure 3. Top: Docked structure of Cdc25A (1C25) and dysidiolide. The highlighted residues are Cys 430, Glu 431, and Arg 436. Middle: Conformer 668, the midpoint conformer of the black-shaded cluster shown in Figure 2 (see also Table 1 for evidence that MD samples particularly relevant conformational space for the Cdc25A/AChE/11HSD PSSC cluster in this time regime). Bottom: Structural overlay (DaliLite) of conformer 668 of Cdc25A following MD simulation (blue) with acetylcholinesterase $(1 \mathrm{H} 22$, red) and $11 \beta-H S D 1$ (1XSE, green). VAST finds this triplet only after the initial 1 C25 coordinates are allowed to relax through MD.

ing core of the receptor; namely of a domain 1-3 fragment, one unbound ligand (1Q25), [38] and two nearly identical structures with bound M6P (1SZ0 and 1SYO). [39] An initial VAST search of 1Q25 and 1SZ0 revealed few potential PSSC partners (three hits for each structure, see the Supporting Information). Therefore, MD simulations with 1000-ps intervals were performed on domains $1-3$ of both the ligand-unbound (1Q25) and ligand-bound (1SZ0) structures. In the for- 


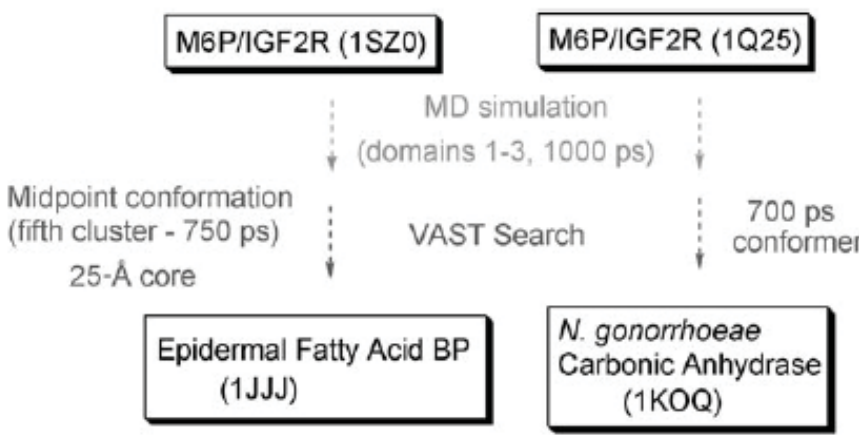

Figure 4. MD-assisted clustering procedure for the cation-indepedent mannose 6-phosphate/insulin-like growth factor II receptor. $\mathrm{BP}=$ binding protein.

mer case, conformers were arbitrarily sampled at 100-ps intervals and subjected directly to VAST searches. The 700-ps conformer identified the interesting carbonic anhydrase (CA) from $N$. gonorrhoeae (1KOQ) [40] as a potential cluster partner for this M6P receptor.

The ligand-bound conformers were clustered by domain 3 , and VMD-extracted [41] 25- $\AA$ cores (centered on C5 of the M6P ligand) from midpoint conformers of the 10 most populated clusters were subjected to VAST searches. From the fifth cluster, a connection to epidermal fatty acid binding protein (E-FABP) emerged. E-FABP belongs to a family of lipid-binding proteins that are associated with fatty acid signaling, cell growth, and cell differentiation. E-FABP is known to be overexpressed in hyperproliferative skin diseases, such as psoriasis, [42] and also appears to be a cancer marker. [43] For these reasons, this target appears to be an excellent PSS cluster partner for the M6P-IGF2R. Neither $N$. gonorrhoe$a e$, CA, nor E-FABP were identified by VAST searches without MD. An overlay of the ligand-bound receptor core (750-ps conformer) with E-FABP is presented in Figure 5.

In conclusion, we describe a new clustering procedure for PSSC that exploits MD and the VAST algorithm. This streamlined approach removes serial structure retrieval and visual alignment steps previously required for clustering (Cdc25A PSSC), and opens up new windows to structural neighbors not

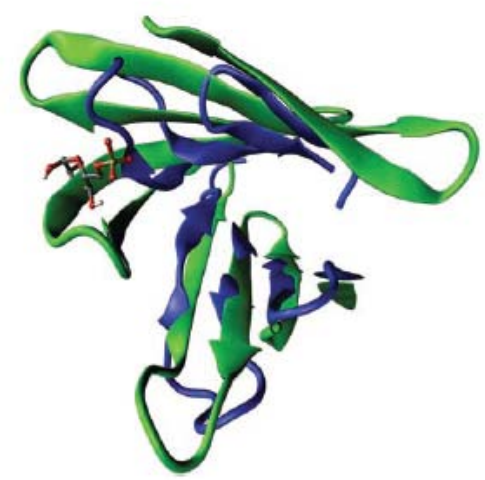

Figure 5. Overlay of the MD-relaxed (750 ps) M6P-IGF2R core (blue) with the human E-FABP (green). The 1SZ0-bound M6P ligand (position at 750 ps) is highlighted with a ball-andstick model. seen when dealing with fixed X-ray crystal structure coordinates (M6P/IGF2R PSSC). Our results suggest that, in general, by treating otherwise static PDB entries as an ensemble of conformers generated by MD, one can sample a broader, and potentially more relevant, swath of protein-structure space when searching for structural partners.

\section{References}

[1] M. A. Koch, H. Waldmann, Drug Discovery Today 2005, 10, 471.

[2] M. A. Koch, L.-O. Wittenberg, S. Basu, D. A. Jeyaraj, E. Gourzoulidou, K. Reinecke, A. Odermatt, H. Waldmann, Proc. Natl. Acad. Sci. USA 2004, 101, 16721.

[3] R. Breinbauer, I. R. Vetter, H. Waldmann, Angew. Chem. 2002, 114, 3002; Angew. Chem. Int. Ed. 2002, 41, 2878.

[4] L. Holm, J. Park, Bioinformatics 2000, 16, 566.

[5] J. Fejzo, C. A. Lepre, J. W. Peng, G. W. Bemis, Ajay, M. A. Murcko, J. M. Moore, Chem. Biol. 1999, 6, 755.

[6] J.-F. Gibrat, T. Madej, S. H. Bryant, Curr. Opin. Struct. Biol. 1996, 6, 377.

[7] J.-Y. Ortholand, A. Ganesan, Curr. Opin. Chem. Biol. 2004, 8, 271.

[8] C. Lipinski, A. Hopkins, Nature 2004, 432, 855.

[9] a) D. S. Tan, Nat. Chem. Biol. 2005, 1, 74; b) M. D. Burke, E. M. Berger, S. L. Schreiber, J. Am. Chem. Soc. 2004, 126, 14095; c) M. D. Burke, S. L. Schreiber, Angew. Chem. 2004, 116, 48; Angew. Chem. Int. Ed. 2004, 43, 46.

[10] A. Noeren-Mueller, I. Reis-Correa, Jr., H. Prinz, C. Rosenbaum, K. Saxena, H. J. Schwalbe, D. Vestweber, G. Cagna, S. Schunk, O. Schwarz, H. Schiewe, H. Waldmann, Proc. Natl. Acad. Sci. USA 2006, 103, 10606.

[11] a) A. M. Boldi, Curr. Opin. Chem. Biol. 2004, 8, 281; b) D. J. Newman, G. M. Cragg, K. M. Snader, J. Nat. Prod. 2003, 66, 1022; c) M.-L. Lee, G. Schneider, J. Comb. Chem. 2001, 3, 284.

[12] a) G. Klebe, Drug Discovery Today 2006, 11, 580; b) N. Weskamp, D. Kuhn, E. Huellermeier, G. Klebe, Bioinformatics 2004, 20, 1522.

[13] A. Shulman-Peleg, R. Nussinov, H. J. Wolfson, J. Mol. Biol. 2004, 339, 607.

[14] T. A. Binkowski, L. Adamian, J. Liang, J. Mol. Biol. 2003, 332, 505.

[15] M. Stahl, C. Taroni, G. Schneider, F. Hoffmann, Protein Eng. 2000, 13, 83 .

[16] K. Kinoshita, J. i. Furui, H. Nakamura, J. Struct. Funct. Genomics 2002, 2, 9.

[17] A. Stark, S. Sunyaev, R. B. Russell, J. Mol. Biol. 2003, 326, 1307.

[18] N. D. Gold, R. M. Jackson, J. Mol. Biol. 2006, 355, 1112.

[19] R. B. Russell, P. D. Sasieni, M. J. E. Sternberg, J. Mol. Biol. 1998, 282, 903.

[20] B. M. McArdle, M. R. Campitelli, R. J. Quinn, J. Nat. Prod. 2006, 69, 14.

[21] E. B. Fauman, J. P. Cogswell, B. Lovejoy, W. J. Rocque, W. Holmes, V. G. Montana, H. Piwnica-Worms, M. J. Rink, M. A. 
Saper, Cell 1998, 93, 617.

[22] M. A. Lyon, A. P. Ducruet, P. Wipf, J. S. Lazo, Nat. Rev. Drug Discovery 2002, 1, 961.

[23] a) I. N. Shindyalov, P. E. Bourne, Nucleic Acids Res. 2001, 29, 228; b) I. N. Shindyalov, P. E. Bourne, Protein Eng. 1998, 11, 739.

[24] L. Holm, C. Sander, Nucleic Acids Res. 1996, 24, 206.

[25] J. Zuegg, K. Gruber, M. Gugganig, U. G. Wagner, C. Kratky, Protein Sci. 1999, 8, 1990.

[26] U. Ermler, C. H. Hagemeier, A. Roth, U. Demmer, W. Grabarse, E. Warkentin, J. A. Vorholt, Structure 2002, 10, 1127.

[27] a) A. Andreeva, D. Howorth, S. E. Brenner, T. J. P. Hubbard, C. Chothia, A. G. Murzin, Nucleic Acids Res. 2004, 32, D 226; b) L. Lo Conte, S. E. Brenner, T. J. P. Hubbard, C. Chothia, A. G. Murzin, Nucleic Acids Res. 2002, 30, 264; c) A. G. Murzin, S. E. Brenner, T. Hubbard, C. Chothia, J. Mol. Biol. 1995, 247, 536.

[28] S. P. Gunasekera, P. J. McCarthy, M. Kelly-Borges, E. Lobkovsky, J. Clardy, J. Am. Chem. Soc. 1996, 118, 8759.

[29] a) W. Sherman, T. Day, M. P. Jacobson, R. A. Friesner, R. Farid, J. Med. Chem. 2006, 49, 534; b) C. A. Sotriffer, O. Kraemer, G. Klebe, Proteins Struct. Funct. Bioinf. 2004, 56, 52.

[30] D. S. Goodsell, A. J. Olson, Proteins Struct. Funct. Genet. 1990, 8, 195.

[31] X. Daura, K. Gademann, B. Jaun, D. Seebach, W. F. VanGunsteren, A. E. Mark, Angew. Chem. 1999, 111, 249; Angew. Chem. Int. Ed. 1999, 38, 236.

[32] D. M. Wong, H. M. Greenblatt, H. Dvir, P. R. Carlier, Y.-F. Han, Y.-P. Pang, I. Silman, J. L. Sussman, J. Am. Chem. Soc. 2003, 125, 363.

[33] D. Ogg, B. Elleby, C. Norstroem, K. Stefansson, L. Abrahmsen, U. Oppermann, S. Svensson, J. Biol. Chem. 2005, 280, 3789 .
[34] a) A. B. Hassan, Am. J. Pathol. 2003, 162, 3; b) J. C. Byrd, J. H. Y. Park, B. S. Schaffer, F. Garmroudi, R. G. MacDonald, J. Biol. Chem. 2000, 275, 18647; c) R. G. MacDonald, S. R. Pfeffer, L. Coussens, M. A. Tepper, C. M. Brocklebank, J. E. Mole, J. K. Anderson, E. Chen, M. P. Czech, A. Ullrich, Science 1988, 239, 1134.

[35] a) J. Li, G. G. Sahagian, Oncogene 2004, 23, 9359; b) D. B. O'Gorman, J. Weiss, A. Hettiaratchi, S. M. Firth, C. D. Scott, Endocrinology 2002, 143, 4287; c) G. R. Hankins, A. T. De Souza, R. C. Bentley, M. R. Patel, J. R. Marks, J. D. Iglehart, R. L. Jirtle, Oncogene 1996, 12, 2003.

[36] S. J. York, L. S. Arneson, W. T. Gregory, N. M. Dahms, S. Kornfeld, J. Biol. Chem. 1999, 274, 1164.

[37] D. B. Berkowitz, G. Maiti, B. D. Charette, C. D. Dreis, R. G. MacDonald, Org. Lett. 2004, 6, 4921.

[38] L. J. Olson, R. D. Yammani, N. M. Dahms, J.-J. P. Kim, EMBO J. 2004, 23, 2019.

[39] L. J. Olson, N. M. Dahms, J.-J. P. Kim, J. Biol. Chem. 2004, 279, 34000 .

[40] S. Huang, Y. Xue, E. Sauer-Eriksson, L. Chirica, S. Lindskog, B.-H. Jonsson, J. Mol. Biol. 1998, 283, 301.

[41] W. Humphrey, A. Dalke, K. Schulten, J. Mol. Graphics 1996, 14, 33 .

[42] G. Siegenthaler, R. Hotz, D. Chatellard-Gruaz, S. Jaconi, J. H. Saurat, Biochem. Biophys. Res. Commun. 1993, 190, 482.

[43] a) L. H. Gutierrez-Gonzalez, C. Ludwig, C. Hohoff, M. Rademacher, T. Hanhoff, H. Ruterjans, F. Spener, C. Lucke, Biochem. J. 2002, 364, 725; b) P. Sinha, G. Hutter, E. Kottgen, M. Dietel, D. Schadendorf, H. Lage, Electrophoresis 1999, 20, 2952. 
Protein Structure Similarity Clusters (PSSC): Dynamic Treatment of PDB Structures Facilitates Clustering

Bradley D. Charette, Richard G. MacDonald, Stefan Wetzel, David B. Berkowitz*, and Herbert Waldmann*

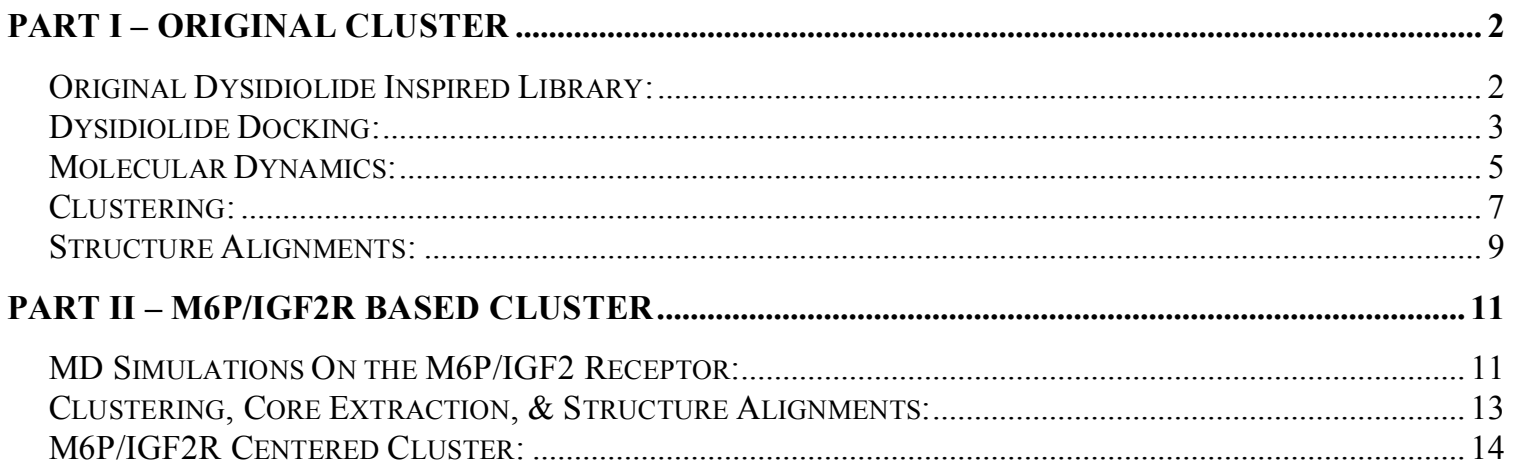




\section{Original Dysidiolide-Inspired Library:}

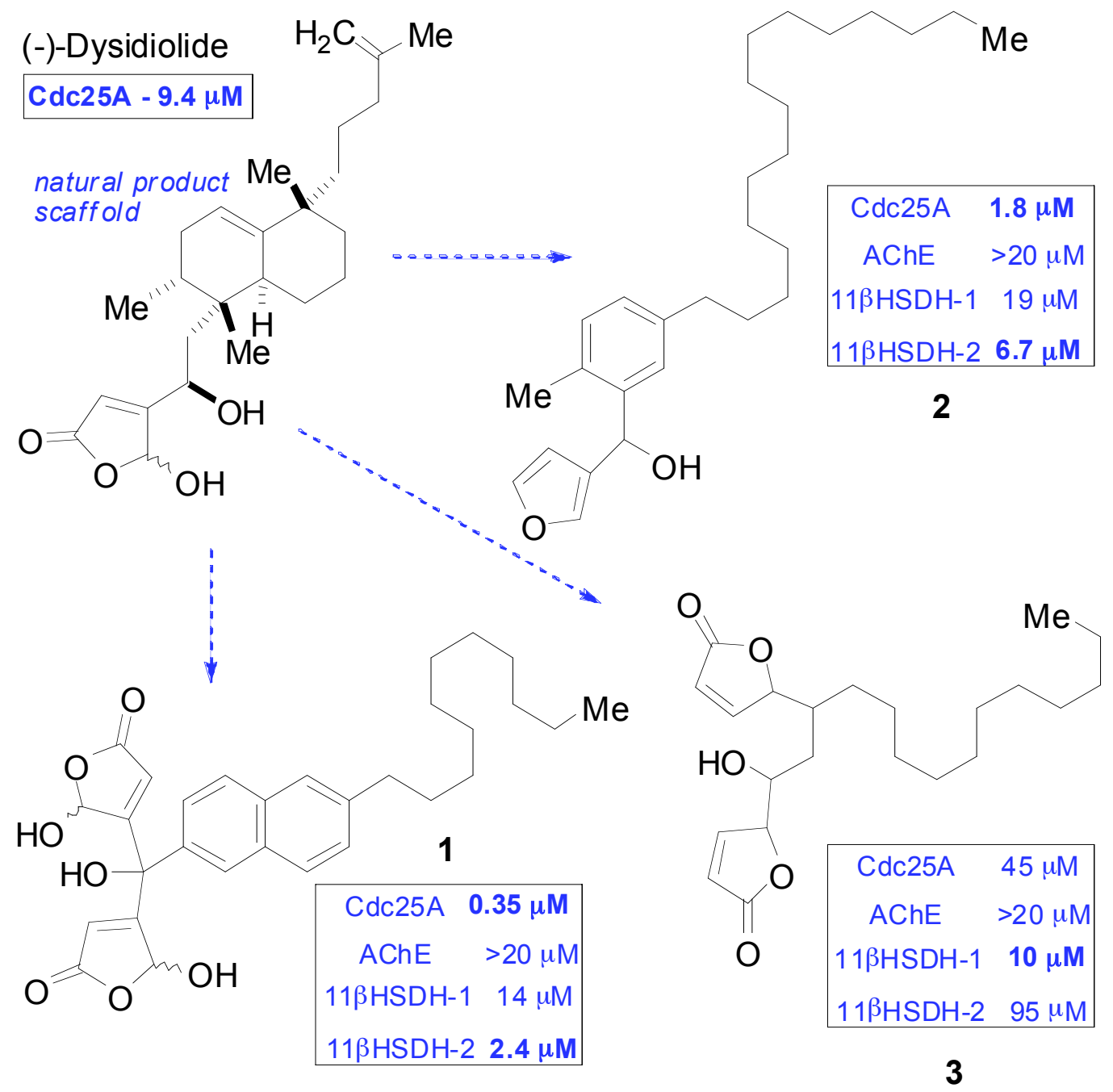

Figure S1 Original dysidiolide-inspired library including inhibition data for Cdc25A, AChE, $11 \beta \mathrm{HSDH}-1$, and $11 \beta \mathrm{HSDH}-2$. 
Dysidiolide Docking: The atomic coordinates for Cdc25A were taken from $1 \mathrm{C} 25^{[1]}$, the only available Cdc25a crystal structure. This structure represents the catalytically active fragment of Cdc25a. The crystal structure was prepared for docking and eventual molecular dynamics simulation by repairing missing atoms from sidechains: K470, K356, K396, and K377, using Tripos Sybyl. For docking, polar hydrogens and partial charges were added using Autodock Tools.

Dysidiolide (Fig. S1) was prepared for docking using Accelrys Materials Studio for building, minimizing, and assignment of partial charges. Dysidiolide was further processed using Autodock Tools to merge non-polar hydrogens and assign rotable bonds.

For docking, an $80 \times 80 \times 80$ point gridmap ( 0.375 angstrom spacing) centered on the active site sulfur of C430, was generated with Autodock 3.0. 100 docking runs (genetic algorithm/local search, 250,000 max energy evals/run) were performed with Autodock 3.0 and the best scoring docked conformer of dysidiolide was chosen as the starting conformer for a molecular dynamics simulation.

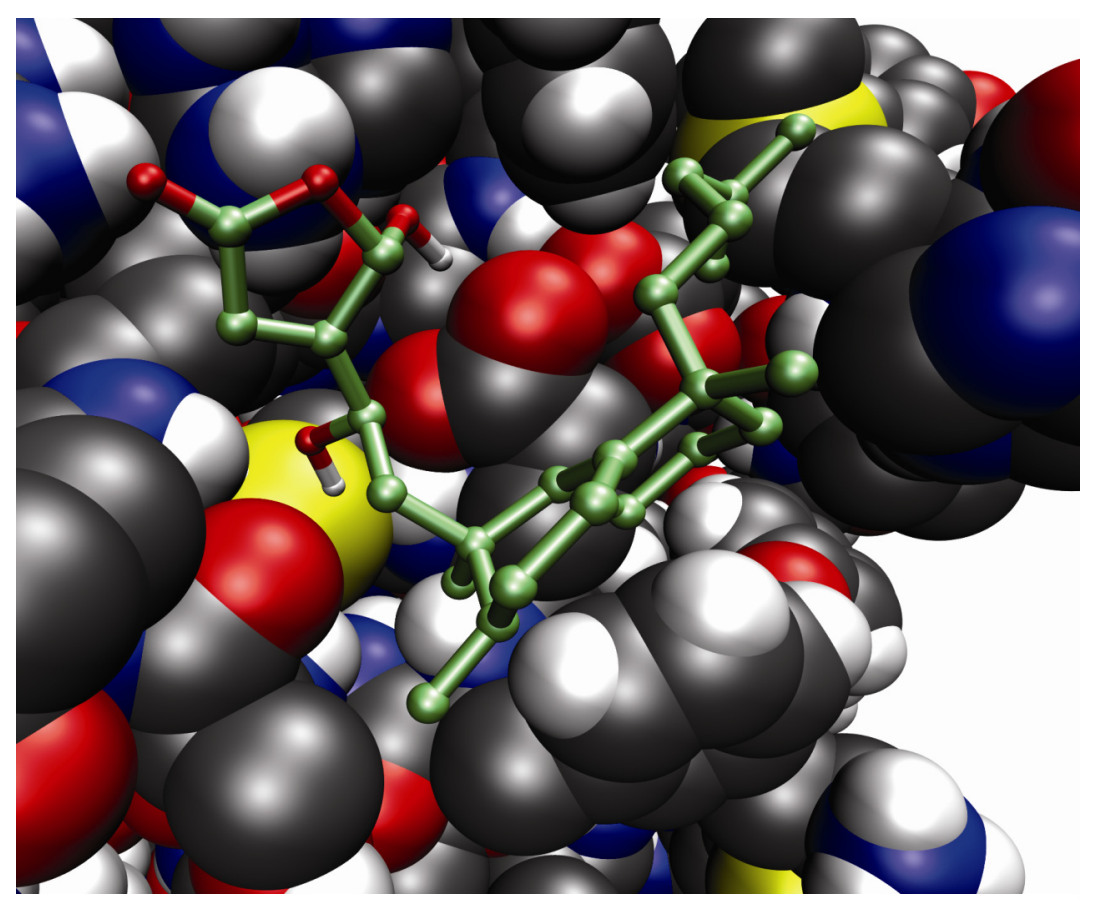

Figure S2 (-)-Dysidiolide docked to the active site of Cdc25A. 


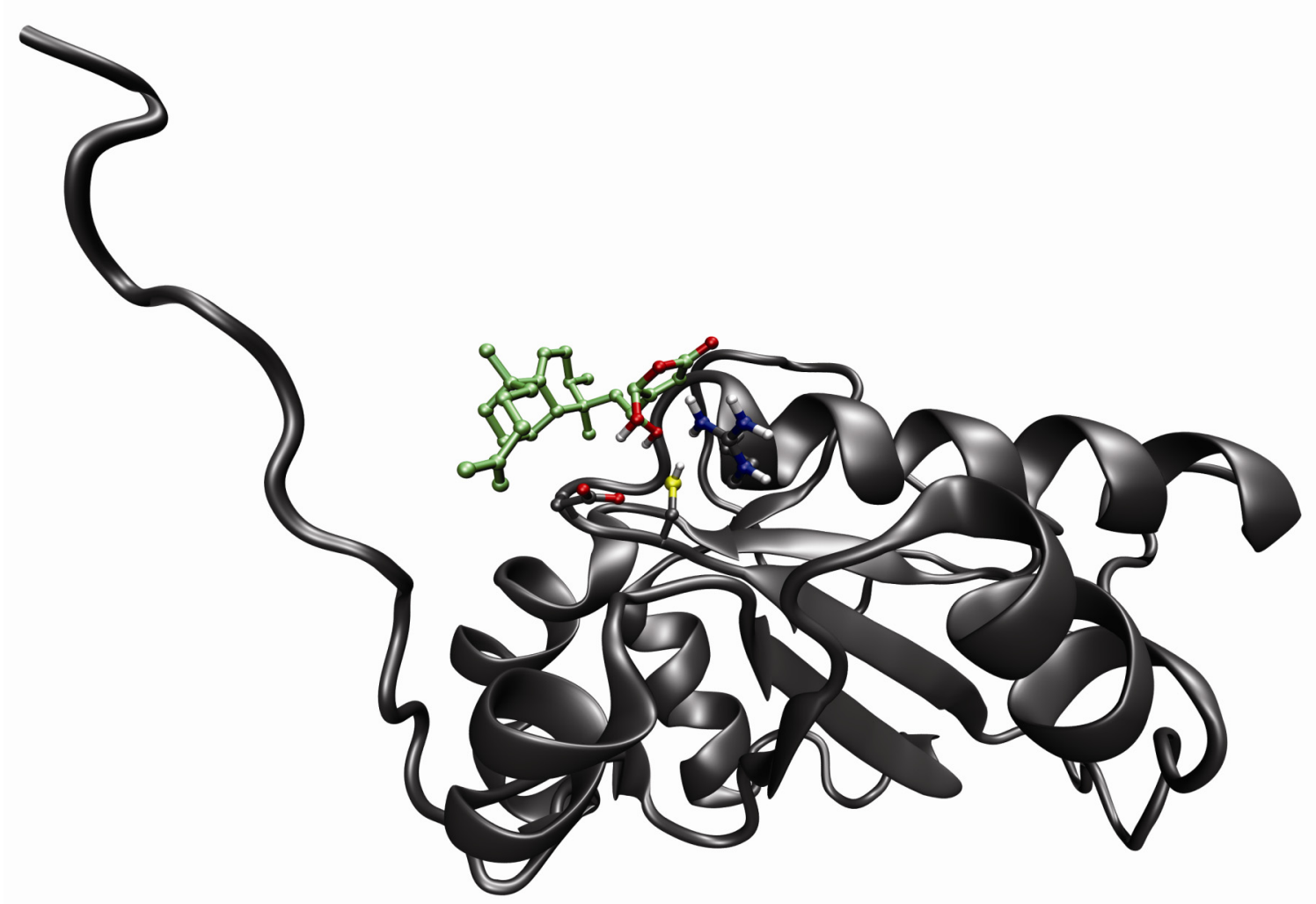

Figure S3 (-)-Dysidiolide docked to Cdc25A catalytic core, with key active site residues (C430, E431, and R436) visible.

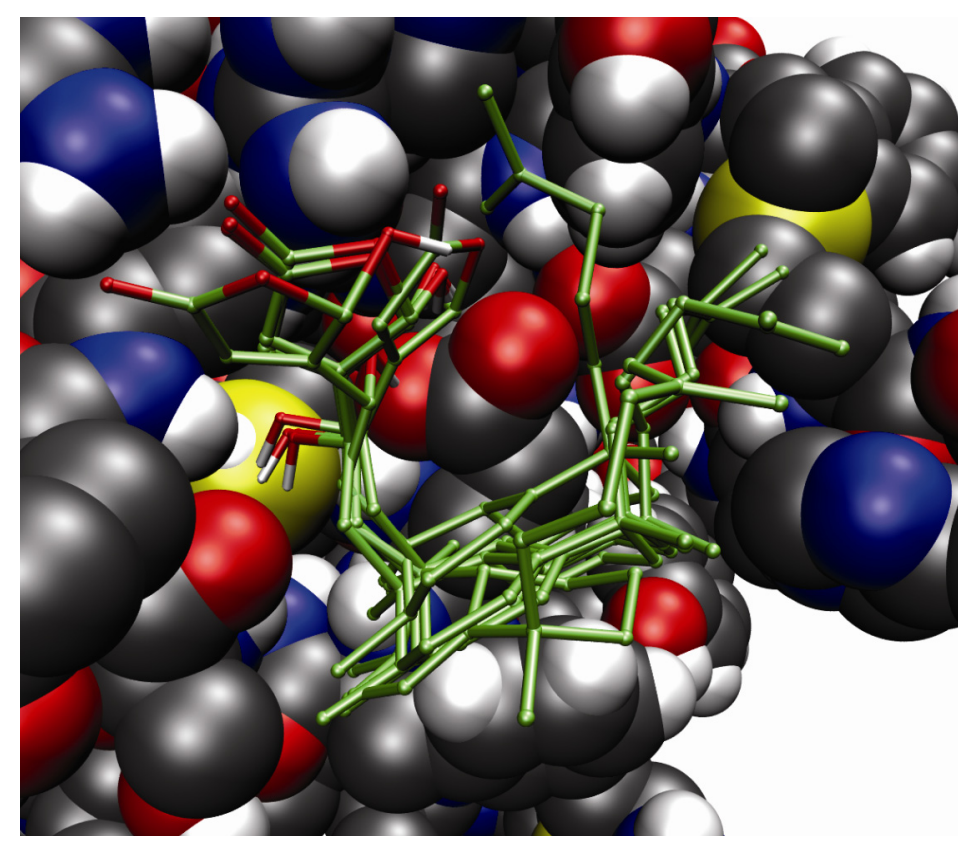

\begin{tabular}{|l|c|c|}
\hline & $\begin{array}{c}\text { Binding } \\
\text { affinity } \\
\text { (kcal/mol) }\end{array}$ & $\begin{array}{c}\text { Docking } \\
\text { affinity } \\
\text { (kcal/mol) }\end{array}$ \\
\hline 1 & -7.23 & -9.69 \\
2 & -6.77 & -8.99 \\
3 & -5.27 & -7.91 \\
4 & -6.13 & -7.59 \\
5 & -4.95 & -6.84 \\
\hline
\end{tabular}

Figure S4 Top-scoring cluster of docking results (based on Autodock predicted binding affinity, left). Autodock predicted binding and docking affinities for members of the docked cluster (right). 
Molecular Dynamics: A dysidiolide topology was generated using ProDRG ${ }^{[2]}$ and the Gromos 96.1 force field. Cdc25A was then solvated in a virtual water box containing 12,920 water molecules. A net charge of -2 was neutralized by replacing two water molecules with 2 sodium ions. Next, a 500 step, steepest decent energy minimization was performed on the system using Gromacs 3.3. ${ }^{[3]}$ The system was then subjected to a 20 picosecond position-restrained "soaking" molecular dynamics simulation. During this simulation, the positions of the Cdc25A and dysidiolide atoms were restrained, while allowing water molecules to relax freely. After the above mentioned

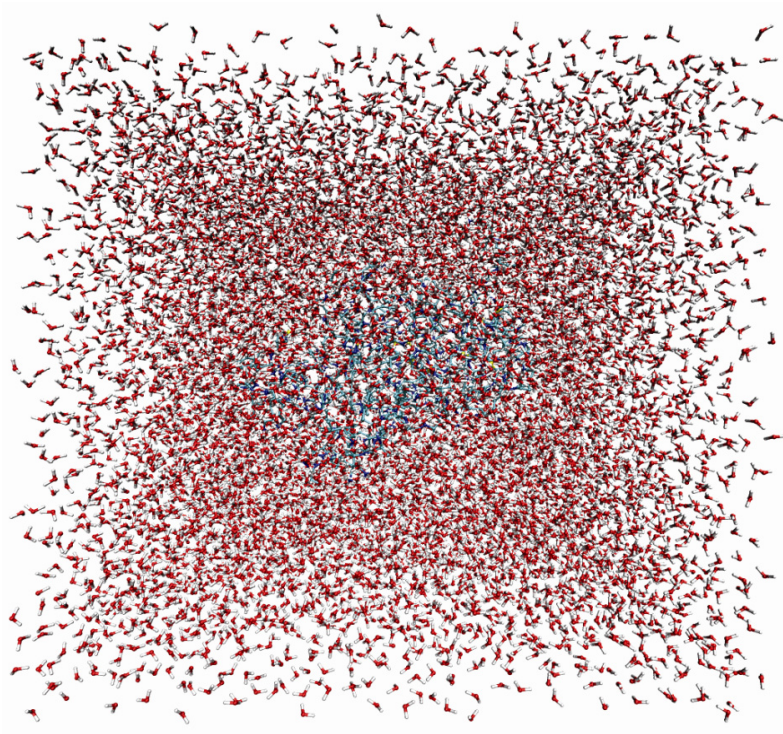

Figure S5 Solvated Cdc25A.

"soaking", the entire system was subjected to an unrestrained molecular dynamics simulation for 1 nanosecond. The trajectory was recorded at one picosecond time points for subsequent analysis.

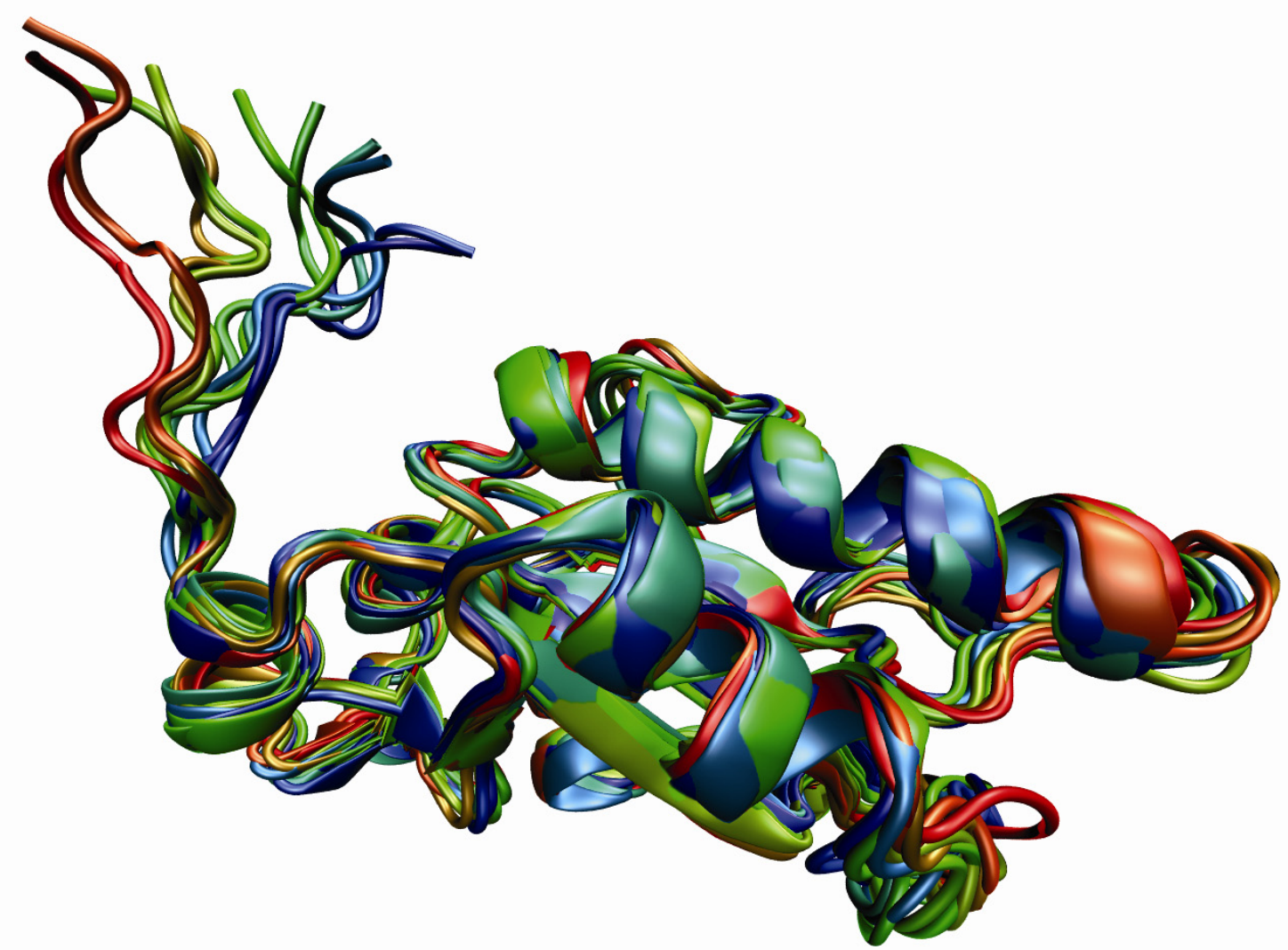

Figure S6 Overlay of conformers taken at 100 picosecond timepoints during the Cdc25A MD simulation. Color scales with time from red ( $0 \mathrm{ps} / \mathrm{Start})$, to green (Middle), to blue ( $1 \mathrm{~ns} / \mathrm{End})$. 


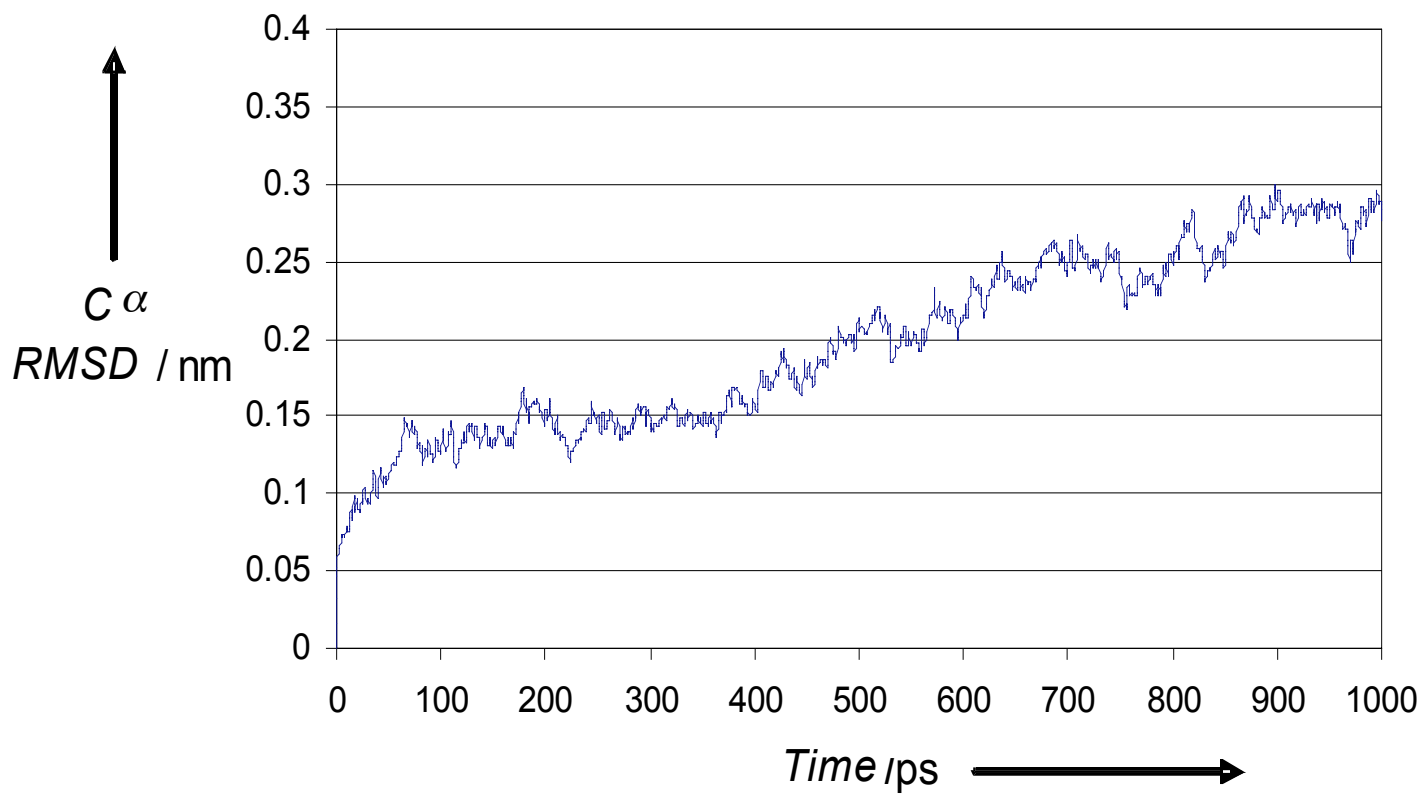

Figure S7 RMSD change in Cdc25A's Ca backbone over time (after least squares alignments).

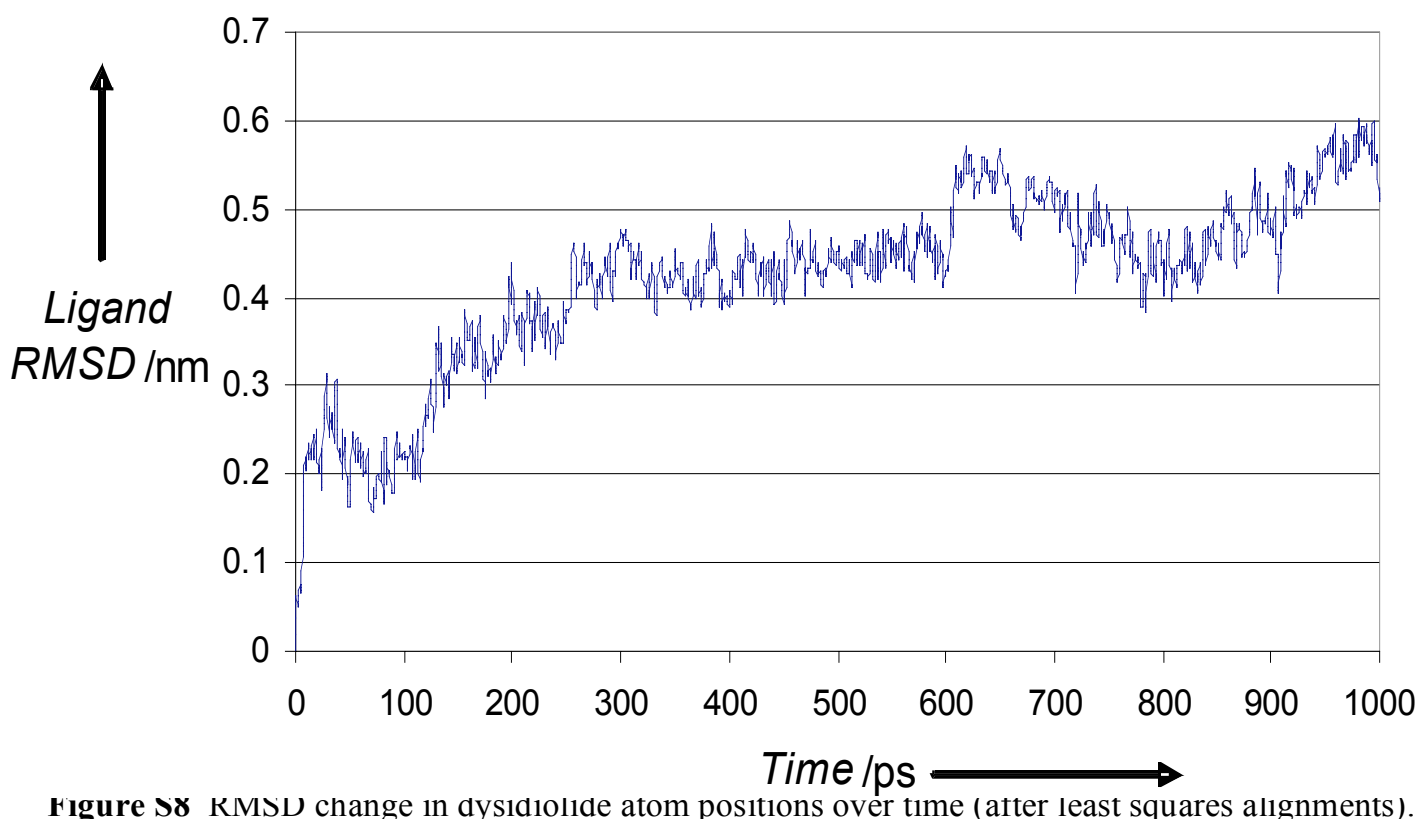


Clustering: Conformational clustering was performed on the molecular dynamics trajectory of Cdc25A in order to intelligently select representative conformations for use in structure alignment searches. Clustering was performed using $\mathrm{C} \alpha$ backbone atoms, least squares alignment, and the Gromos algorithm ${ }^{[4]}$ (cutoff: $0.75 \AA$ ) as implemented by Gromacs 3.3. This method creates clusters so that the midpoint conformation of a given cluster is within a $0.75 \AA \mathrm{C} \alpha \mathrm{RMSD}$ of any member in that cluster. The $0.75 \AA$ cutoff distance was arrived at by an iterative process. Clustering with cutoffs of 1.0 and $0.5 \AA$ were also examined, but gave either too few (heavily populated), or too many (lightly populated) clusters, respectively. Midpoint conformations of the top 10 most populated clusters were saved for further use in structure alignment searches.

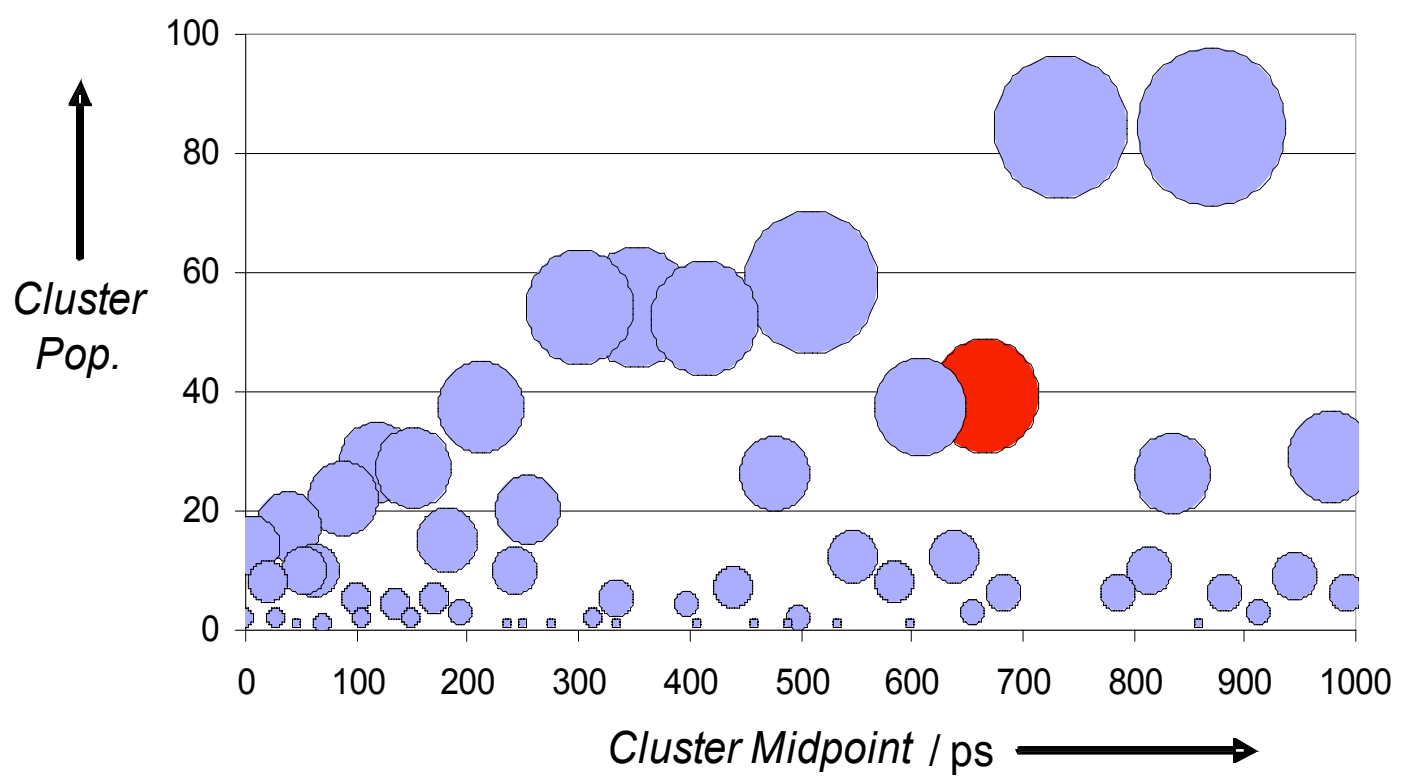

Figure S9 Chart displaying cluster population vs midpoint after clustering with the Gromos algorithm and a $0.75 \AA$ cutoff. Sixty total clusters were generated. Highlighted in red is the $7^{\text {th }}$ most populated cluster which has a midpoint conformation occurring at 668 picoseconds into the simulation. This conformation provided the best alignment to AChE and 11 $\beta$-HSD, upon submission to VAST. 


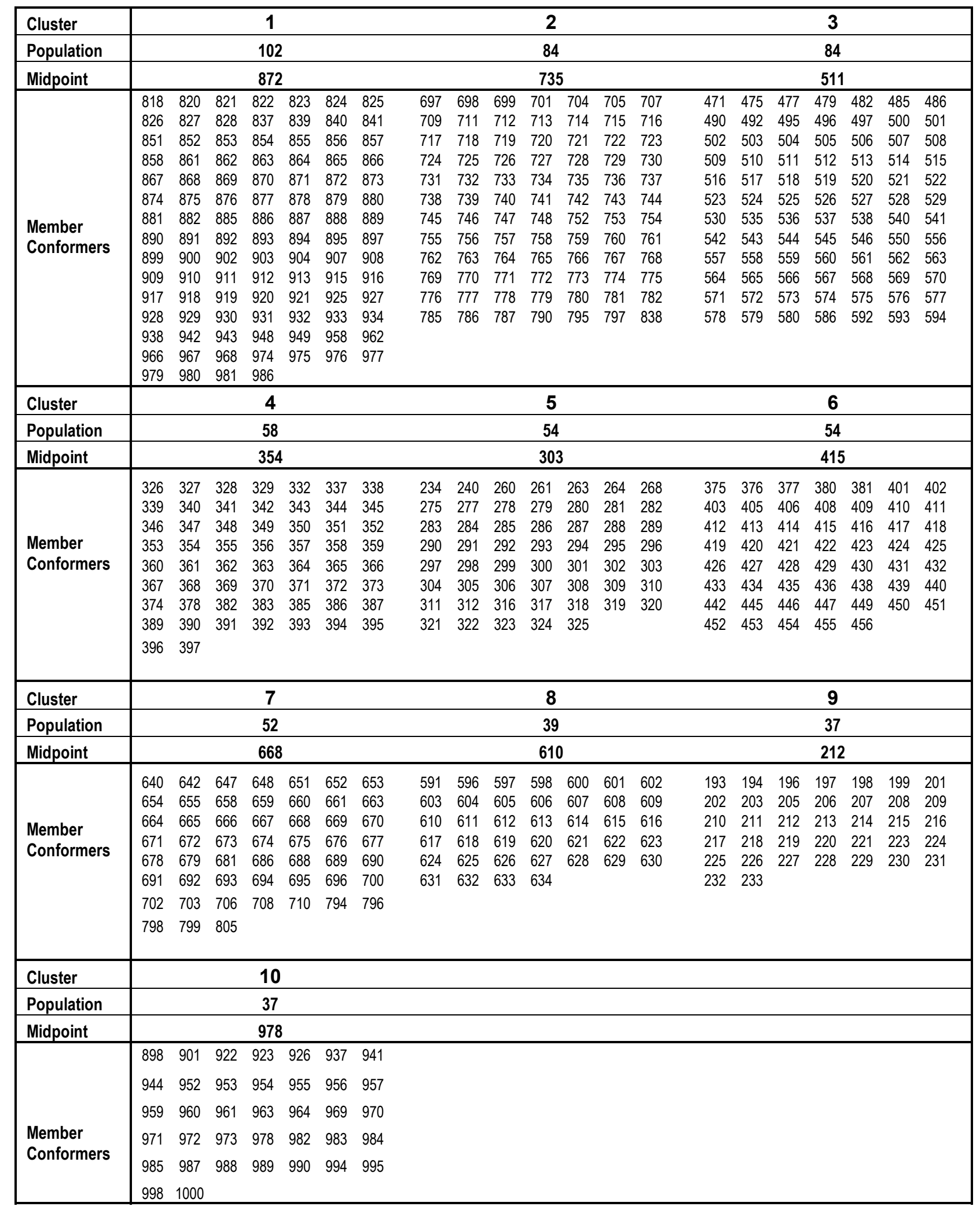

Figure S10 Members of the top 10 most populated conformation clusters for Cdc25A. The numbers given in the Member Conformers box correspond to the picosecond timepoints in the simulation at which given conformers were recorded. 
Structure Alignments: Midpoint conformations from each cluster, along with conformers taken at 100 ps timepoints throughout the simulation, were submitted to the Vector Alignment Search Tool (VAST) ${ }^{[5]}$ available on NCBI's website. Results from each search were then screened for matches against $11 \beta$ hydroxysteroid dehydrogenase, types $1 \& 2$ $(11 \beta \mathrm{HSD})$, acetylcholine esterase (AChE), tropinone reductase, hydroxynitrile lyase, and methylene-tetrahydromethanopterin dehydrogenase (MTHMP DH). In addition to VAST alignments, Cdc25A was aligned to AChE and 11ßHSD structures at 100 ps intervals using DaliLite. ${ }^{[6]}$

\begin{tabular}{|c|c|c|c|c|c|c|c|}
\hline \multicolumn{3}{|c|}{$\begin{array}{c}\text { Structure submitted for } \\
\text { Alignment }\end{array}$} & \multicolumn{5}{|c|}{ VAST Structure Alignment Results } \\
\hline & & & \multirow{2}{*}{$\begin{array}{c}\text { AChE } \\
66 \\
\end{array}$} & \multirow{2}{*}{$\begin{array}{c}\text { 11ק-HSD } \\
6\end{array}$} & \multirow{2}{*}{$\begin{array}{c}\text { Trop } \\
\text { Red. } \\
6\end{array}$} & \multirow{2}{*}{$\begin{array}{c}\text { OH Nitrile } \\
\text { Lyase } \\
23\end{array}$} & \multirow{2}{*}{$\begin{array}{c}\text { MTHMP } \\
\text { DH } \\
2 \\
\end{array}$} \\
\hline & Members & $\begin{array}{c}\text { Midpoint } \\
\text { (ps) }\end{array}$ & & & & & \\
\hline Cluster 1 & 102 & 872 & & & & 22 & 2 \\
\hline Cluster 2 & 84 & 735 & & & & 5 & \\
\hline Cluster 3 & 84 & 511 & & & & 12 & \\
\hline Cluster 4 & 58 & 354 & & & & 20 & 1 \\
\hline Cluster 5 & 54 & 303 & & & & 17 & \\
\hline Cluster 6 & 54 & 415 & & & & 1 & \\
\hline Cluster 7 & 52 & 668 & 14 & 1 & 3 & 22 & 2 \\
\hline Cluster 8 & 39 & 610 & & & & 22 & 2 \\
\hline Cluster 9 & 37 & 212 & & & & 2 & \\
\hline Cluster 10 & 37 & 978 & & & & 2 & \\
\hline \multicolumn{8}{|l|}{$0 \mathrm{ps}$} \\
\hline $100 \mathrm{ps}$ & & & & & & 17 & \\
\hline 200 ps & & & & & & 1 & \\
\hline 300 ps & & & & & & 20 & 2 \\
\hline 400 ps & & & & & & 18 & \\
\hline 500 ps & & & & & & 22 & 2 \\
\hline $600 \mathrm{ps}$ & & & & & & 20 & 2 \\
\hline 700 ps & & & 1 & & 2 & 21 & 2 \\
\hline 800 ps & & & 1 & & & 22 & 2 \\
\hline 900 ps & & & & & & 22 & 2 \\
\hline $1000 \mathrm{ps}$ & & & & & & 17 & 2 \\
\hline
\end{tabular}

Figure S11 Results of VAST structure alignments for selected conformers. Results are listed as the number of matches against acetylcholine esterase, $11 \beta$ hydroxysteroid dehydrogenase, hydroxy nitrile lyase, and methylene-tetrahydromethanopterin dehydrogenase. The total number of PDBdeposited structures for each protein is listed in blue. The conformer at $668 \mathrm{ps}$, the midpoint of cluster 7 , provided the most matches, and is highlighted in red.

The midpoint conformer of cluster 7, which occurs at 668 picoseconds, matches 14 of 66 acetylcholine esterase structures and 1 of $611 \beta$ hydroxysteroid dehydrogenase structures in the PDB. Since this conformer was the only conformer tested that provided VAST hits against $11 \beta$ hydroxysteroid dehydrogenase, a closer look was given to the residues responsible for the overlay. Figure S12 displays a plot of the RMSD change over time in the aligned portion of conformation 668. During the period from 600 to 700 picoseconds in the simulation, these residues appear to undergo a sharp change in alignment and it is suspected that this movement may be responsible for the success of conformation 668 in aligning with 
11ßHSD. A similar plot (Figure S13), tracks the RMSD change in regions of 668 which align with AChE (structure:1H22). This plot provides no apparent explanation the conformers at 668,700 , or 800 ps aligning to acetylcholine esterase.

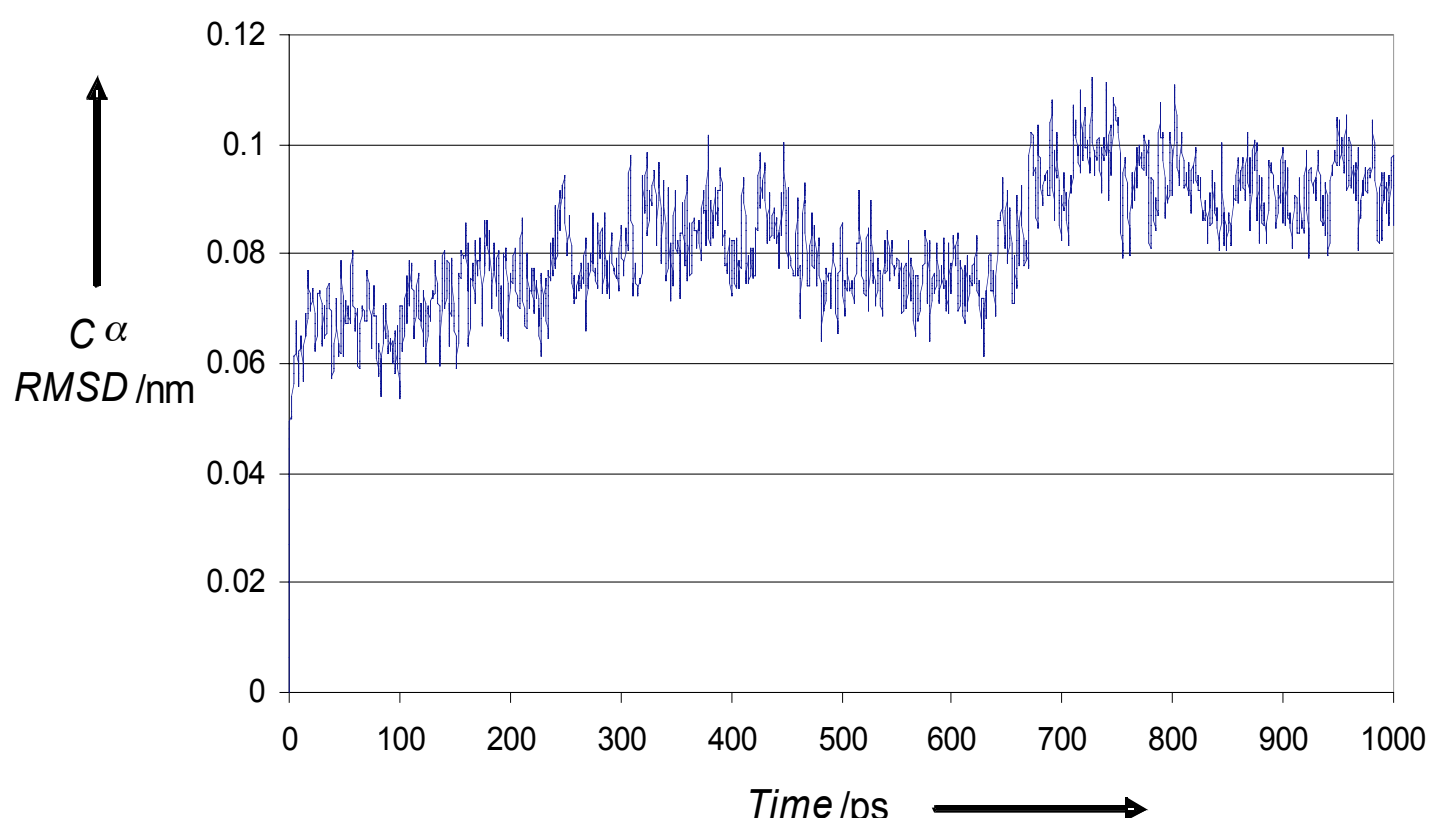

Figure S12 RMSD, over time, of the C $\alpha$ backbone of Cdc25A which align to $11 \beta$ hydroxysteroid dehydrodgenase (1XSE).

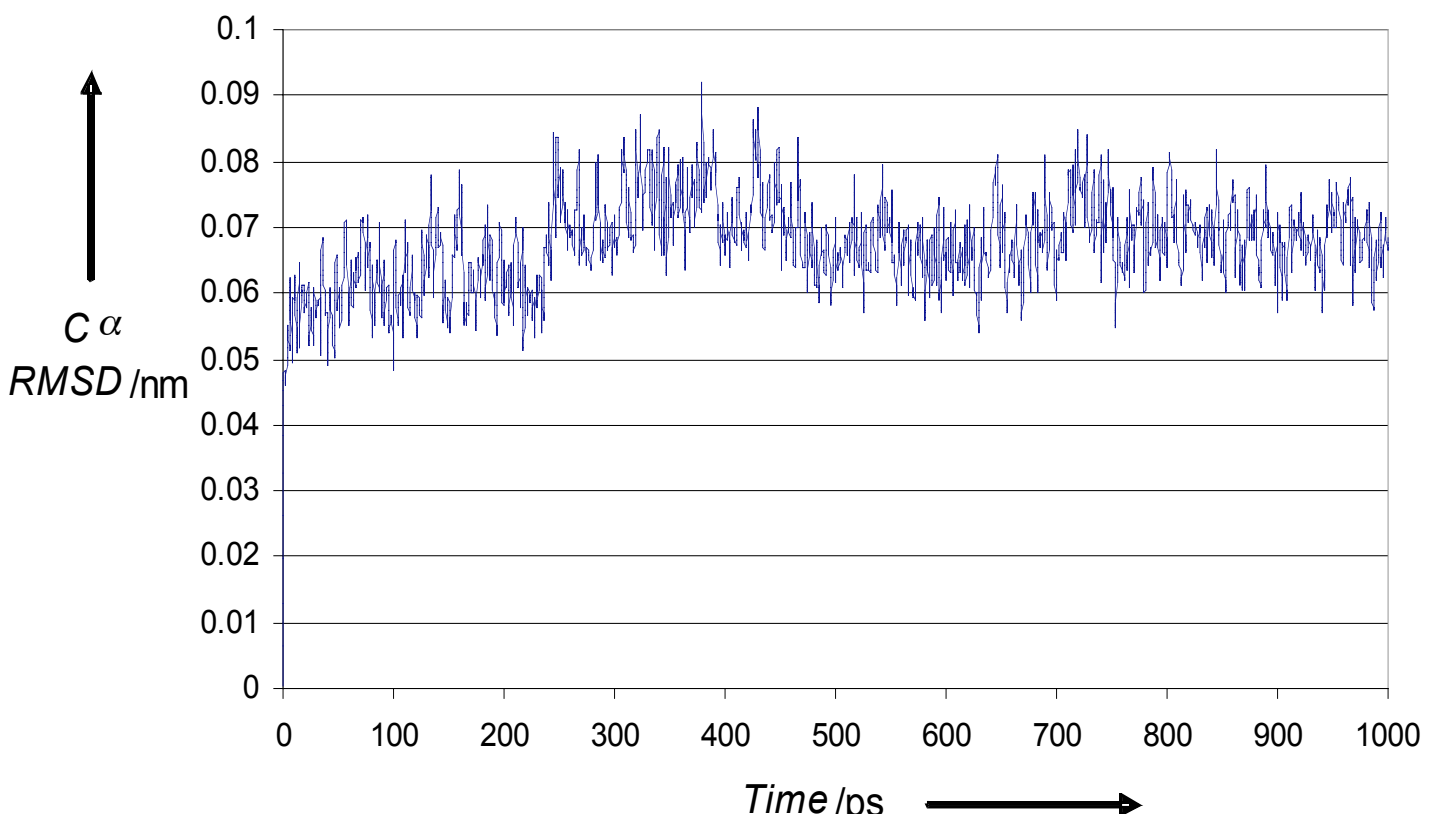

Figure S13 RMSD, over time, of the Cdc25A's C $\alpha$ backbone which aligns to acetylcholine esterase (1H22). 
MD Simulations on the M6P/IGF2 Receptor: Since there are both ligand bound $\left(1 \mathrm{SZ0} 0^{[7]}\right)$ and ligand unbound $\left(1 \mathrm{Q} 25^{[8]}\right)$ crystal structures available for the N-terminal three domain construct of the M6P/IGF2R, both were chosen for molecular dynamics simulations. Chain $\mathrm{B}$ was chosen from 1SZ0, as it exhibited fewer missing residues than chain A. Missing atoms and residues from 1SZ0 chain B and 1Q25 were repaired using Tripos Sybyl. Using the coordinates of mannose 6-phosphate from the 1SZ0 crystal structure, a Gromos 96.1 force field topology was generated using ProDRG.

The procedure for the molecular dynamics simulations on ligand bound and unbound M6P/IGF2 receptor were identical to that for Cdc25A. Structures were first solvated, net charge neutralized, then energy minimized by 500 step steepest decent method, soaked during 20 ps of position restrained molecular dynamics, then subjected to an unrestrained molecular dynamics simulation for 1 nanosecond, all using the Gromacs 3.3 software package.

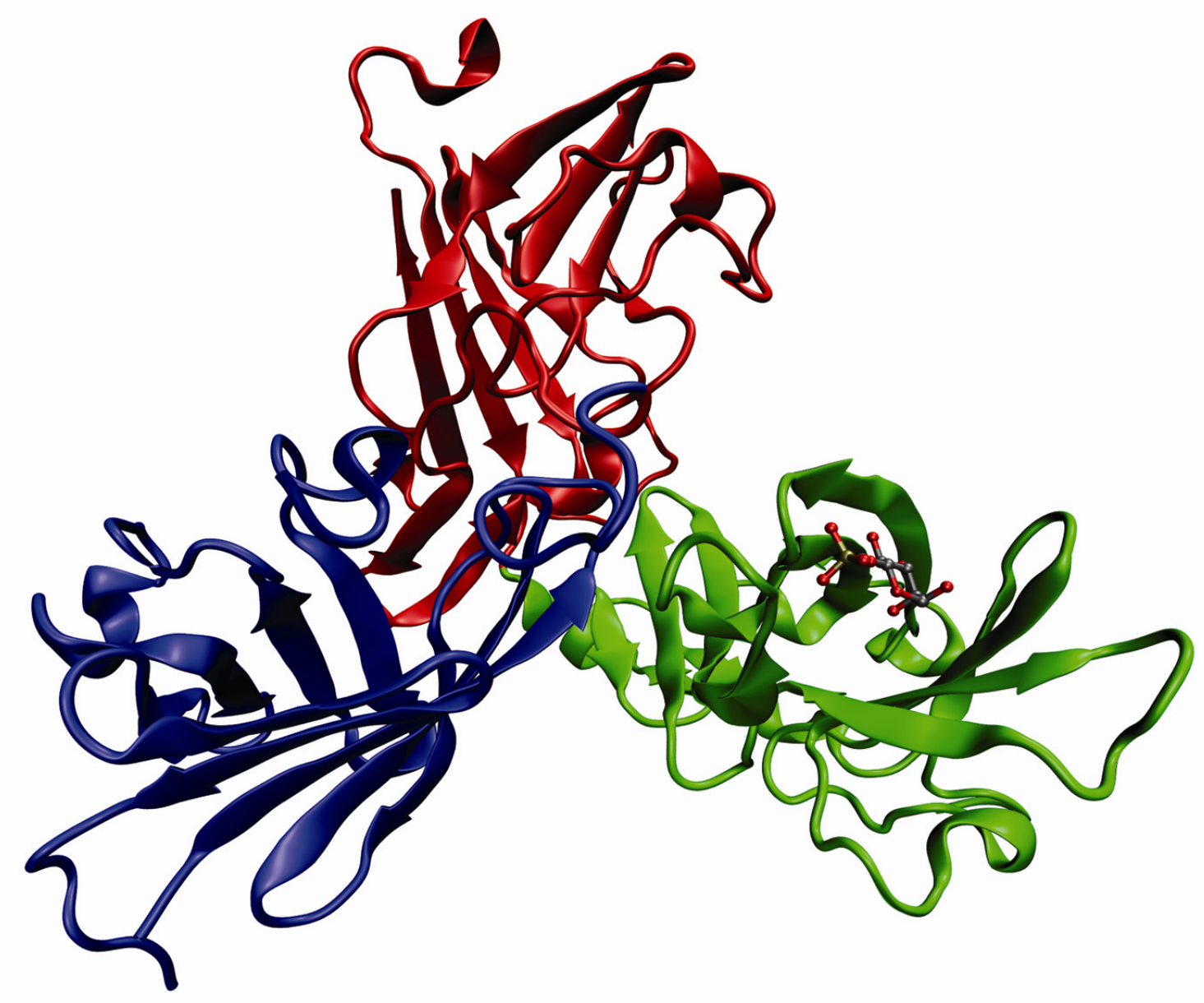

Figure S14 Crystal structure of the N-terminal 3 domains of the M6P/IGF2R bound to mannose 6phosphate (1SZ0 chain B). Domain 3 (green) forms a binding site for mannose 6-phosphate. Domains 1 (blue) and 2 (red) have also been described as necessary for formation of a high-affinity pocket.

As seen in Figure S14, domain 3 of the M6P/IGF2R appears to be the primary site of M6P interaction with the N-terminal 3 domain construct. Based on this, the C $\alpha$ RMSD of domain 
3 residues was tracked over the course of both ligand bound and unbound simulations. Plots of these changes can be seen in Figures S15 and S16.

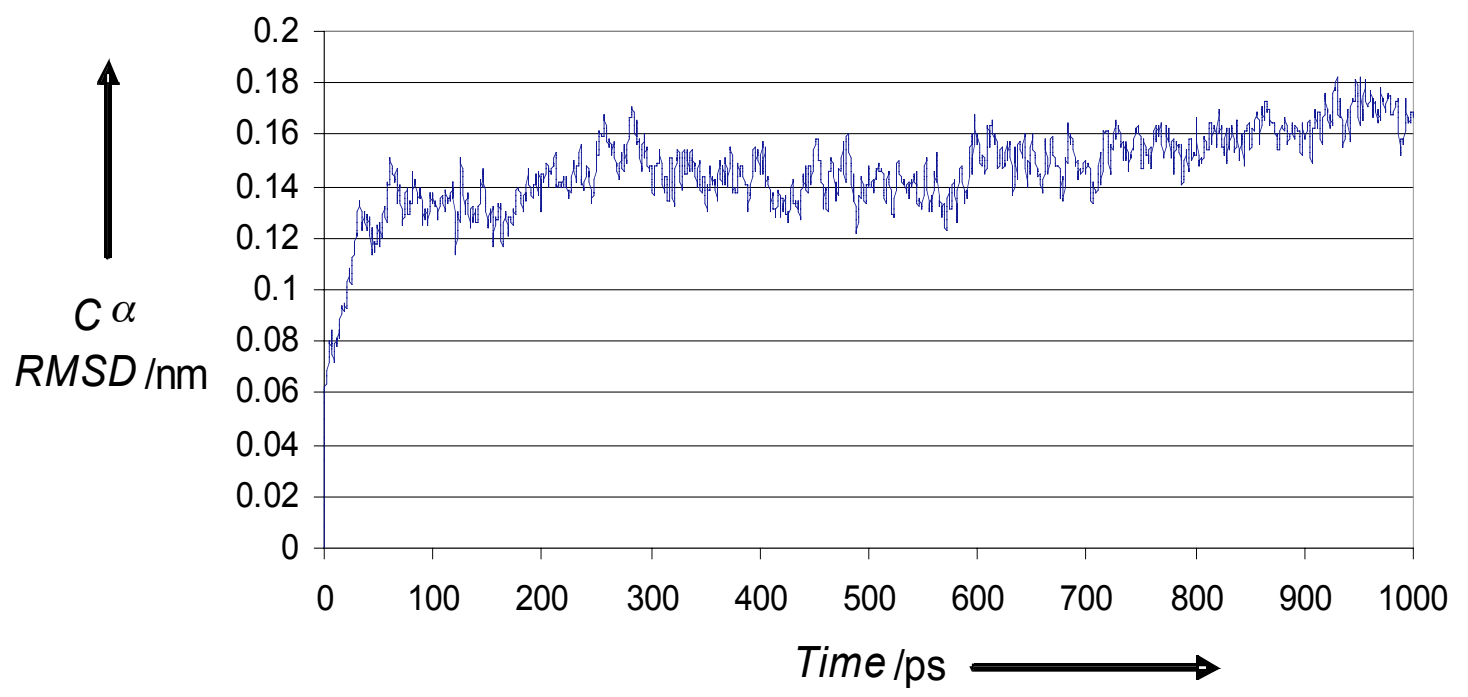

Figure S15 Plot of the change over time in C-alpha RMSD (after least squares alignments) for domain 3 residues of the M6P/IGF2R ligand bound molecular dynamics simulation.

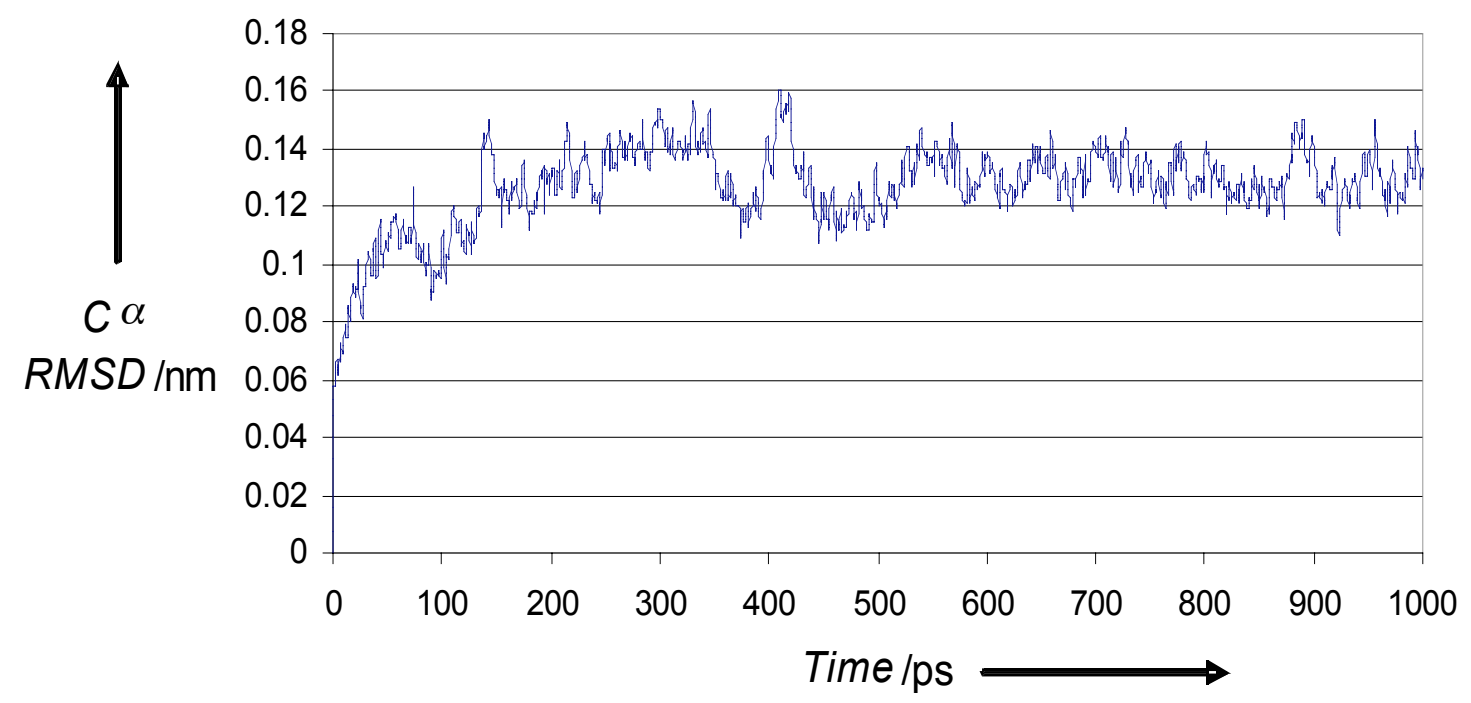

Figure S16 Plot of the change over time in C-alpha RMSD (after least squares alignments) for domain 3 residues of the M6P/IGF2R ligand free molecular dynamics simulation. 
Clustering, Core Extraction, \& Structure Alignments: The N-terminal 3 domains of the M6P/IGF2R have few initial matches in structure alignment searches. This could be due to the limited number of membrane-bound receptor crystal structures in the PDB. In fact, VAST searches on domain 3 of the ligand free structure (1Q25) result in only 3 alignments from VAST's low redundancy data set. The aligned proteins comprise: N9 Tern Influenza Neuraminidase (1XOG), Metallo $\beta$-Lactamase II (2BC2), and Flavoprotein TM0755 from Thermotoga maritima (1VME). A search on domain 3 of the ligand bound structure (1SZ0 chain B) yields 3 results, as well. These are: Lectin-1 from Trichosanthes kirilowii (1GGP), Polyadenylate Polymerase from Vaccinia Virus (2GA9), and Flavoprotein TM0755 from Thermotoga maritima (1VME).

Representatives are chosen for the low redundancy subset based on BLAST $p$ values of $10^{-7}$ relative to other members contained in a representative group. Counting structural neighbors from just this subset streamlines the process of filtering out multiple hits from identical or nearly identical proteins. With this in mind, conformations taken at $100 \mathrm{ps}$ intervals from each MD simulation were submitted to VAST to see if MD simulation could expand the range of structural neighbors.

\begin{tabular}{|c|l|c|l|l|c|}
\hline \multirow{2}{*}{} & \multicolumn{2}{|c|}{ Ligand Free } & & \multicolumn{2}{c|}{ Ligand Bound } \\
\cline { 2 - 6 } & Structure & $\begin{array}{c}\text { L.R. } \\
\text { VAST } \\
\text { Hits }\end{array}$ & Structure & $\begin{array}{c}\text { L.R. } \\
\text { VAST } \\
\text { Hits }\end{array}$ \\
\hline $\begin{array}{c}\text { Native } \\
\text { Structure }\end{array}$ & $1 \mathrm{Q} 25$ & 3 & & 1 SZ0 B & 3 \\
\hline \multirow{5}{*}{$\begin{array}{c}\text { MD } \\
\text { Generated }\end{array}$} & $100 \mathrm{ps}$ & 2 & $100 \mathrm{ps}$ & 8 \\
& $200 \mathrm{ps}$ & 7 & $200 \mathrm{ps}$ & 11 \\
& $300 \mathrm{ps}$ & 14 & $300 \mathrm{ps}$ & 8 \\
& $400 \mathrm{ps}$ & 8 & $400 \mathrm{ps}$ & 2 \\
& $500 \mathrm{ps}$ & 8 & $500 \mathrm{ps}$ & 8 \\
& $600 \mathrm{ps}$ & 3 & $600 \mathrm{ps}$ & 8 \\
& $700 \mathrm{ps}$ & 4 & $700 \mathrm{ps}$ & 5 \\
& $800 \mathrm{ps}$ & 4 & & $800 \mathrm{ps}$ & 6 \\
& $900 \mathrm{ps}$ & 16 & $900 \mathrm{ps}$ & 10 \\
& $1000 \mathrm{ps}$ & 1 & & $1000 \mathrm{ps}$ & 3 \\
\hline
\end{tabular}

Figure S17 Results of VAST searches on conformers from both ligand bound and ligand free simulations. Results are listed as the number of structural neighbors (to domain 3) identified in VASTs low redundency data set.

From this initial search, it can be seen that taking conformers from multiple time points in the simulation dramatically improves the number of VAST-identified structural neighbors.

To provide a more focused search for structural neighbors of the M6P binding pocket, binding cores were extracted from conformers generated during the ligand bound M6P/IGF2R simulation. First, clusters were generated using only $\mathrm{C} \alpha$ coordinates from domain 3 residues and the Gromos algorithm as implemented by Gromacs 3.3. This clustering method was chosen to provide the best chance of identifying the most unique conformations of domain 3, independent of any changes in domains 1 and 2 which might bias the clustering procedure. Then, a $25 \AA$ core was extracted from the midpoint conformation of 
each of the 10 most populated clusters. This was achieved by cutting out a $25 \AA$ sphere, centered on the $\mathrm{C}^{5}$ ring carbon of M6P, using Visual Molecular Dynamics (VMD) ${ }^{[9]}$. These $25 \AA$ cores were then subjected to VAST searches.

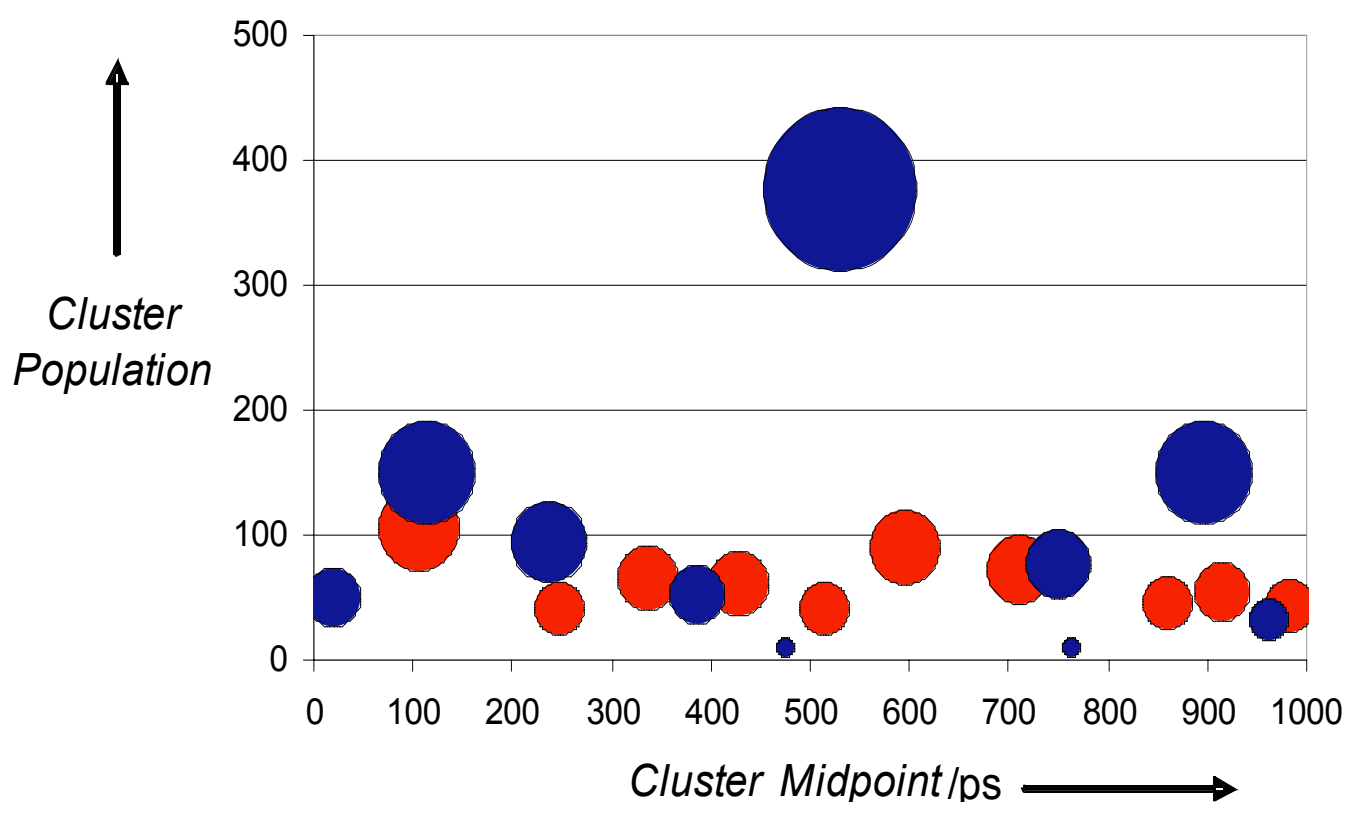

Figure S18 Clusters resulting from domain 3-based clustering are depicted in blue. Clustering based on domains 1-3 are colored in red. The most frequently sampled conformation of domain 3 (cluster 1 midpoint: 531 ps) would not be apparent if all 3 domains were used for clustering.

M6P/IGF2R Centered Cluster: After analyzing VAST search results from various arbitrary (100 ps time point) conformations, refined by extraction of $25 \AA$ cores, a potential PSSC cluster of M6P/IGF2R, carbonic anydrase (coordinates: $1 \mathrm{KOQ}^{[10]}$ ), and epidermal fatty acid binding protein (E-FABP, coordinates: $1 \mathrm{JJJ}^{[11]}$ ) was identified.
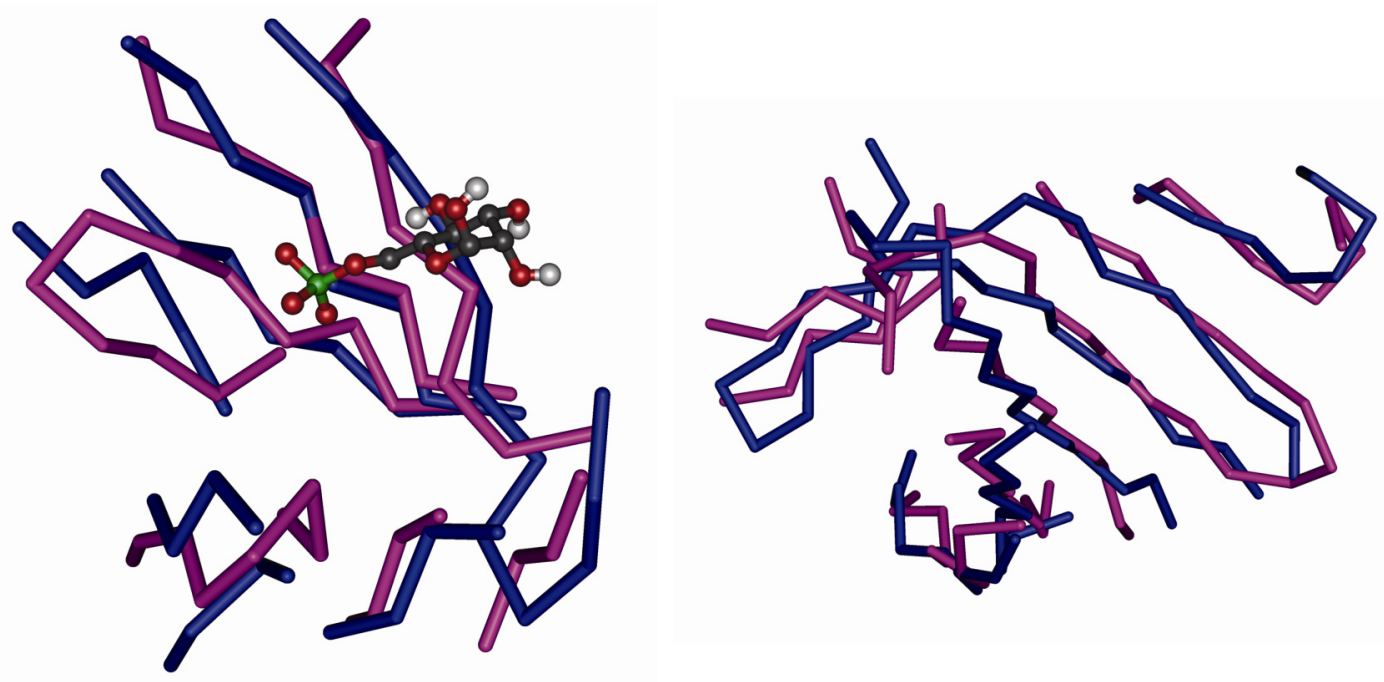

Figure S19 VAST aligned backbones for the $25 \AA$ cluster 5 core aligned with E-FABP/1JJJ (left) and the ligand unbound $700 \mathrm{ps}$ conformer aligned with carbonic anhydrase/1KOQ (right). 


\begin{tabular}{|l|c|c|c|c|c|c|}
\hline Search Structure & Match & $\begin{array}{c}\text { Aligned } \\
\text { Length }\end{array}$ & RMSD & $\begin{array}{c}\text { VAST } \\
\text { Score }\end{array}$ & p value & $\begin{array}{c}\text { \%Sequence } \\
\text { ID }\end{array}$ \\
\hline $\begin{array}{l}\text { Ligand Free } \\
700 \text { ps conformer }\end{array}$ & $1 \mathrm{KOQ}$ & 70 & 2.9 & 10.9 & 0.0187 & 2.9 \\
\hline $\begin{array}{l}\text { Ligand Bound - cluster } 5 \\
\text { midpoint - 25 angstrom } \\
\text { core }\end{array}$ & $1 \mathrm{JJJ}$ & 44 & 3.2 & 8.3 & 0.0313 & 6.8 \\
\hline
\end{tabular}

Figure S20 VAST statistics for M6P/IGF2R alignments with carbonic anhydrase (coordinates: 1KOQ) and epidermal fatty acid binding protein (coordinates:1JJJ).

[1] E. B. Fauman, J. P. Cogswell, B. Lovejoy, W. J. Rocque, W. Holmes, V. G. Montana, H. Piwnica-Worms, M. J. Rink, M. A. Saper, Cell 1998, 93, 617.

[2] A. W. Schuttelkopf, D. M. F. van Aalten, Acta Crystallographica Section DBiological Crystallography 2004, 60, 1355.

[3] E. Lindahl, B. Hess, D. van der Spoel, J. Molecular Modeling 2001, 7, 306.

[4] K. G. Xavier Daura, Bernhard Jaun, Dieter Seebach, Wilfred F. van Gunsteren, Alan E. Mark, Angew. Chem. 1999, 111, 249; Angew. Chem. Int. Ed. 1999, 38, 236.

[5] J. F. Gibrat, T. Madej, S. H. Bryant, Curr. Op. Struct. Biol. 1996, 6, 377.

[6] L. Holm, J. Park, Bioinformatics 2000, 16, 566.

[7] L. J. Olson, N. M. Dahms, J. J. Kim, J. Biol. Chem. 2004, 279, 34000.

[8] L. J. Olson, R. D. Yammani, N. M. Dahms, J. J. Kim, EMBO J. 2004, 23, 2019.

[9] W. Humphrey, A. Dalke, K. Schulten, J. Mol. Graphics 1996, 14, 33.

[10] S. Huang, Y. Xue, E. Sauer-Eriksson, L. Chirica, S. Lindskog, B.-H. Jonsson, J. Mol. Biol. 1998, 283, 301.

[11] L. H. Gutierrez-Gonzalez, C. Ludwig, C. Hohoff, M. Rademacher, T. Hanhoff, H. Ruterjans, F. Spener, C. Lucke, Biochem J 2002, 364, 725. 